\title{
Depletion of Fractalkine Ameliorates Renal Injury and Treg Cell Apoptosis via the p38MAPK Pathway in Lupus-Prone Mice
}

\section{Jingxue Ma}

Affiliated Hospital

Qiming Gong

Affiliated Hospital

Pengwei Guo

Affiliated Hospital

Xiuhong Pan

Affiliated Hospital

\section{Linlin $\mathrm{He}$}

Affiliated Hospital

Yanwu You ( $\square$ youyanwu@163.com )

Youjiang Medical University for Nationalities https://orcid.org/0000-0002-2612-5317

\section{Research}

Keywords:

Posted Date: November 13th, 2020

DOI: https://doi.org/10.21203/rs.3.rs-104559/v1

License: (9) (1) This work is licensed under a Creative Commons Attribution 4.0 International License. Read Full License 


\section{Abstract \\ Background}

Fractalkine is a chemokine with several roles, including chemotaxis, adhesion, and immune damage. It participates in cell inflammation and apoptosis and responds to the pathogenesis of autoimmune diseases. On the other hand, Treg cells are involved in autoimmune diseases. This study aimed to explore the regulatory mechanism of Fractalkine in renal injury and Treg apoptosis via the p38MAPK signalling pathway in lupus-prone mice.

\section{Methods}

Lupus was induced in BALB/c female mice by injection of pristane. Then, $\mathrm{CD} 4^{+} \mathrm{CD} 5^{+}$Treg cells were isolated from the spleen of lupus mice. To deplete Fractalkine, first, mice received an injection of anti-Fractalkine antibody. Later, the transfection of Treg cells with Fractalkine siRNA was conducted. Lupus mice and Treg cells were treated with the p38MAPK inhibitor SB203580 and/or activator U-46619, respectively. The levels of urine protein, serum urea nitrogen, creatinine, and autoantibodies were measured from mouse samples, and renal histopathological features were analysed. The expression of Fractalkine, p-p38, Foxp3, IL-6, and IL-17 in the mouse kidney and Treg cells was detected. The levels of apoptosis and key apoptotic factors: Bax, Bcl-2, and Cyt-c in Treg cells were analysed.

\section{Results}

The expression of Fractalkine, p-p38, IL-6, and IL-17 increased; meanwhile, that of Foxp3 decreased in the kidneys of mice with lupus. The depletion of Fractalkine and p38MAPK levels ameliorated proteinuria and renal functions and significantly reduced serum autoantibodies, renal Fractalkine, p-p38, IL-6, and IL-17 levels, while increasing renal Foxp3 concentration in lupus mice. The effects of Fractalkine knockdown (KD) and p38MAPK inhibitor on Treg cells, derived from lupus mice, were consistent with those observed in the kidneys. In addition, Fractalkine KD reduced cell apoptosis and suppressed the activation of p38MAPK signalling in Treg cells, derived from lupus mice. Meanwhile, the p38MAPK activator U-46619 had the opposite effect.

\section{Conclusion}

Together, our data indicated that Fractalkine promoted the nephritis progression in lupus mice, most likely through the regulation of Treg cell apoptosis and activation of the p38MAPK signalling pathway. It suggested that targeting Fractalkine is a potential therapeutic strategy for treating LN.

\section{Background}

Systemic lupus erythematosus (SLE) is a chronic autoimmune disease with multiple organ dysfunctions. Lupus nephritis (LN) is a crucial and fatal complication of SLE [1]. Recent research has shown favourable properties of T lymphocytes and chemokines in the development of LN [2,3]. However, the exact molecular mechanisms involved in LN onset remain to be elucidated.

Regulatory T (Treg) cells, characterised by their cell surface markers: CD4, CD25, and Foxp3, are present in the peripheral blood and spleen and mediate remarkable immunosuppressive effects $[4,5]$. The importance of regulatory 
T cells in immunoregulation and tolerance development has been well demonstrated $[6,13]$. Specifically, the expression of the transcription factor fork head box p3 (Foxp3) determined the development and differentiation of Treg cells [14], and its increase activated $C D 4^{+} C D 25^{+}$Treg cells in vitro [15]. However, the dysregulation of Tregs is a pivotal factor for the development of LN [13], and a pool of Foxp ${ }^{+}$Treg cells has been associated with LN features. Therefore, these data demonstrated that LN leads to reversible defects in CD $4^{+} \mathrm{CD} 25^{+}$Treg cells and suggest the important therapeutic roles for $\mathrm{CD} 4^{+} \mathrm{CD} 25^{+}$Treg cells in LN patients. Fractalkine (CX3CL1), a unique member of the CX3C chemokine superfamily, is mainly involved in cell adhesion, growth regulation, and inflammatory immune response [16]. Fractalkine plays a significant role in tissue injury and in the accumulation of immune cells during the development of LN [17]. Fractalkine has a chemotactic function and is involved in the activation or inactivation of immune cells [18]. Although Fractalkine is widely distributed in vivo, it has high specificity for macrophages (MФ), monocytes $\left(C D 14^{+}\right)$, and lymphocytes $\left(C D 4^{+}\right.$and $\left.C D 8^{+}\right)$, as well as natural killer $\left(C D 16^{+}\right)$, dendritic, and mast [19-23] cells. Furthermore, the Fractalkine expression significantly increased in HK-2 cells, podocytes, and lipopolysaccharidestimulated MRL/Ipr mice, leading to cell and tissue inflammation [24, 25]. These data indicated that Fractalkine could be a potential pathogenic factor for inflammatory diseases.

On the other hand, the p38MAPK signalling pathway is involved in the cell cycle and apoptosis processes. The four main members of the p38MAPK family include p38, MAPK, SAPK4, and stress-activated protein kinase 3 [SAPK3]. Once the p38MAPK pathway is activated by chemokines, the transcription factors, such as p53, PAX6, CREB, and ATF2, are activated to regulate the production of pro-inflammatory responses or apoptosis [26]. P38MAPK phosphorylation is essentially responsible for the production of the $\mathrm{C}-\mathrm{C}$ chemokine, monocyte chemoattractant protein (MCP)-1, which is involved in the pathogenesis of LN [27]. Further studies have shown that the p38MAPK signalling pathway plays a crucial role in the transcription and translation of different components of the P38MAPK signalling pathway before the pro-inflammatory cytokine synthesis, constituting potential therapeutic targets for inflammatory diseases and autoimmune diseases [28-30]. Therefore, the present study focused on the p38MAPK signalling pathway, which has been implicated in LN progression, because it exerts important immune regulatory functions and regulates cell apoptosis and inflammatory responses [31-33].

In this study, we detected the expression of Fractalkine and the activation of the p38MAPK signalling pathway in the kidneys of lupus mice. Subsequently, we examined whether the expression of the Fractalkine-p38MAPK signalling axis led to Treg apoptosis and reduction of Foxp3 expression. Our findings may constitute a key step in the pathogenesis of Treg dysfunction and could provide further insights on potential targets for therapeutic intervention of LN.

\section{Results}

\section{The lupus mouse model was successfully established}

To build a lupus mouse model, we used a previously validated method $[13,34,35]$. The levels of proteinuria $(\mathrm{g} / 24 \mathrm{~h})$ $(1.69 \pm 0.33)$, serum urea nitrogen $(B U N)(32.7 \pm 2.8)$, and creatinine $(\mathrm{Cr})(1.45 \pm 0.20)$ were higher in lupus mice than in control mice $(0.55 \pm 0.13,11.33 \pm 1.0,0.33 \pm 0.06$, respectively, $p<0.05)$. Furthermore, the concentrations of ANA, anti-dsDNA, and anti-Sm autoantibodies (Fig. 1a) were significantly increased in the lupus mouse model (53.63 \pm $2.28,57.11 \pm 1.42,61.19 \pm 4.77$, respectively) (Fig. 1b), compared to those of the control mice $(12.17 \pm 0.81,14.43 \pm$ $0.71,6.86 \pm 0.53$, respectively, $p<0.05$ ) (Fig. 1a). Importantly, renal histopathology of lupus mouse tissues showed ischaemic and shrunk glomeruli to varying degrees, glomerular capillary stenosis and occlusion (1), increased mesangial matrix, proliferated mesangial cells, thickened basement membrane (2), degenerated vacuole granules of 
renal tubules (3), and infiltrated inflammatory cells in the renal interstitium (4), compared to those of control mice (Fig. 1c). The results suggested that the lupus mouse model was successfully established, and these mice were used in subsequent studies.

\section{Depletion of Fractalkine and p38MAPK inhibitor, SB203580, ameliorated proteinuria and renal injury and reduced the serum concentration of autoantibodies in lupus mice}

The results obtained for the seven groups are shown in Fig. 2 (a-c). The $24 \mathrm{~h}$ proteinuria and serum Cr and BUN levels of lupus mice significantly increased $(1.81 \pm 0.30,1.44 \pm 0.07$ and $33.93 \pm 3.17)$, compared to those of the control $(0.52 \pm 0.11,0.35 \pm 0.05$ and $10.48 \pm 1.71)$, Fractalkine-depleted $(0.51 \pm 0.13,0.38 \pm 0.11$ and $9.82 \pm 1.44)$, and SB203580 mice $(0.64 \pm 0.13,0.34 \pm 0.06$ and $10.55 \pm 2.17)$, respectively, $p<0.05$. However, the 24 h proteinuria, serum $\mathrm{Cr}$, and BUN levels decreased in the lupus mice when compared to lupus + Fractalkine-depleted $(0.98 \pm 0.10,0.69 \pm$ 0.09 and $21.81 \pm 2.21)$ and lupus + SB203580 mice $(0.97 \pm 0.16,0.67 \pm 0.06$ and $22.94 \pm 2.05)$, respectively, $p<0.05$. Serum Cr and BUN levels in lupus + Fractalkine-depleted + SB203580 mice $(0.53 \pm 0.09,0.35 \pm 0.05$, and 10.7 \pm 1.6$)$, were much lower than those in lupus + Fractalkine-depleted and lupus + SB203580 mice $(p<0.05)$. The lupus mice also exhibited significantly higher levels of ANA (68.69 \pm 4.64$)$, anti-dsDNA (79.56 \pm 7.50$)$, and anti-Sm (54.69 \pm 6.35$)$ than those of the lupus + Fractalkine-depleted $(50.25 \pm 1.95,53.25 \pm 3.28$, and $36.92 \pm 4.25$, respectively), and lupus + SB203580 mice $(50.00 \pm 2.69,54.07 \pm 3.14$, and $34.16 \pm 3.22$, respectively, $p<0.05)$. In lupus + Fractalkine-depleted + SB203580 mice, the serum ANA, ds-DNA, and anti-Sm levels $(25.52 \pm 2.57,25.07 \pm 3.73$, and $21.65 \pm 3.20$, respectively) was lower than those observed in lupus + Fractalkine-depleted and lupus + SB203580 mice $(p<0.05)$ (Fig. 2d). The PASM-stained renal tissues of control, Fractalkine-depleted, and SB203580 mice showed normal renal glomeruli and tubules, in contrast to the histopathological characteristics of lupus mouse model, which was described in the previous section. However, the symptoms of lupus + Fractalkine-depleted and lupus + SB203580 mice were significantly diminished than those of the lupus mice. Importantly, the lupus + Fractalkine-depleted + SB203580 mice showed significantly more reduced kidney injury, than both former groups (Fig. 2e).

\section{Depletion of Fractalkine and p38MAPK inhibitor, SB203580, decreased the levels of renal Fractalkine, p-p38, IL-6, and IL-17, and increased those of renal Foxp3 in lupus mice}

The concentrations of renal Fractalkine, p-p38, Foxp3, IL-6, and IL-17 proteins were compared between the different mouse groups by western blot and immunofluorescence. Western blot results showed a decreased expression of Foxp3 protein in lupus mice, when compared to that of the control mice, but an increased expression in lupus + Fractalkine-depleted and lupus + SB203580 mice, compared to lupus mice $(p<0.05)$ (Fig. 3). While the expression of Fractalkine, p-p38, IL-6, and IL-17 increased in lupus mice compared to control mice, that of lupus + Fractalkinedepleted and lupus + SB203580 mice decreased. Moreover, the Fractalkine, p-p38, IL-6, and IL-17 protein concentrations increased in Foxp3 but decreased in lupus + Fractalkine-depleted + SB203580 mice, when compared to those of lupus + Fractalkine-depleted and lupus + SB203580 mice $(p<0.05)$. The western blot results were further verified by immunofluorescence analysis. To this end, kidney sections of lupus mice were stained with antibodies against Fractalkine, p-p38, and Foxp3 proteins. 
Furthermore, the average optical densities of FKN, p-p38, and Foxp3 are shown in Table 2. This semi-quantitative evaluation indicated that, compared to control mice, the expression of Foxp3 protein decreased in lupus mice, but compared to lupus mice, those levels increased in lupus + Fractalkine-depleted and lupus + SB203580 mice $(p<0.05)$. Fractalkine and p-p38 concentrations increased in lupus mice and decreased in lupus + Fractalkine-depleted and lupus + SB203580 mice. Moreover, the Foxp3 concentration increased and the Fractalkine and p-p38 expression decreased in lupus + Fractalkine-depleted + SB203580 mice, when compared to lupus + Fractalkine-depleted and lupus + SB203580 mice $(p<0.05)$ (Fig. 4).

\section{Fractalkine levels were knocked down in Treg cells derived from the spleen of lupus mice}

$\mathrm{CD} 4^{+} \mathrm{CD} 25^{+}$Treg cells were isolated and purified from the spleen of lupus mice by magnetic bead cell sorting. The purity of $\mathrm{CD} 4^{+} \mathrm{CD} 25^{+} \mathrm{T}$ cells was more than 95\% (Fig. 5a). After optimising the purification method of $\mathrm{CD} 4^{+} \mathrm{CD} 25^{+} \mathrm{T}$ cells, we evaluated the effect of Fractalkine on the apoptosis of $C D 4^{+} C D 25^{+} T$ cells after knocking down its expression. To this end, cells were infected with the lentiviral vector particle-Fractalkine or the hU6-MCS-UbiquitinEGFP-IRES-puromycin scramble negative control. After puromycin screening, the expression levels of Fractalkine were verified by western blot. As shown in Fig. 5b-c, the Fractalkine protein levels in the Fractalkine KD group (0.339 \pm 0.018 ) were significantly lower than those in the control group $(1.000 \pm 0.000, p<0.05)$; meanwhile, those in the negative control group did not change $(0.999 \pm 0.004, p>0.05)$.

\section{Knockdown of Fractalkine levels reduced cells apoptosis and suppressed the activation of p38MAPK signalling in Treg cells derived from lupus mice}

Foxp3 mRNA and protein expression was significantly augmented in Treg cells from the Fractalkine KD lupus mouse after treatment with SB203580. On the other hand, the phosphorylation of p38MAPK was suppressed by Fractalkine KD and SB203580. U-46619 treatment produced the opposite effect than SB203580 in these analyses (Fig. 6a-c).

Annexin V-FITC/PI staining and FC analysis were performed to determine the degree of $\mathrm{CD} 4^{+} \mathrm{CD} 25^{+} \mathrm{T}$ cell apoptosis in all the groups after $48 \mathrm{~h}$ of culture. As shown in Fig. 7a-b, the apoptosis rate significantly decreased in the Fractalkine KD, SB203580, and Fractalkine KD + SB203580 groups, compared to that in the control group $(p<0.05)$, but significantly increased in the U-46619 group $(p<0.05)$. In addition, the apoptosis rates in the control, negative, and Fractalkine KD + U-46619 groups were not significantly different. Taken together, these data showed that SB203580 and Fractalkine KD inhibited the apoptosis of lupus mouse Treg cells, while U-46619 promoted it.

Protein and mRNA expression levels of several key apoptotic genes (Bax, Bcl-2, and Cyt-c) in mouse Treg cells from all groups were detected by western blot and RT-PCR, respectively. Bcl-2 mRNA and protein expression, as contrary to that of Bax and Cyt-C, was augmented in Fractalkine KD and/or SB203580-treated lupus mouse Treg cells. Moreover, treatment with U-46619 elicited the opposite effect (Fig. 7c-e). Taken together, these results suggested that Fractalkine regulated the activation of the p38MAPK signalling pathway to promote apoptosis of lupus mouse Treg cells. 


\section{Discussion}

In this study, we demonstrated that Fractalkine was highly expressed in the kidneys of lupus mice. The inhibition of Fractalkine and p38MAPK signalling increased the levels of Foxp3 and decreased those of pro-inflammatory cytokines, ameliorating the histological damage of the kidneys. In addition, the expression of Foxp3 decreased in lupus mice, while the depletion of Fractalkine promoted the Foxp3 expression and reduced the apoptosis rate of lupus mouse Treg cells by inhibiting the p38MAPK signalling. Our results suggested that targeting the Fractalkinep38MAPK signalling axis could be a potential therapeutic approach for LN.

Treg cells represent a substantial obstacle for immunotherapy, as they regulate the immune balance in both rodents and humans [36]. The quantitative and qualitative defects of Treg cells play a critical role in the pathogenesis of LN. Furthermore, IL-6 plays is involved in regulating the balance between Th17/Treg cells. In the presence of IL-6, natural $\mathrm{CD}^{+} \mathrm{T}$ cells differentiate into Th17 cells (with TGF-a), instead of iTreg cells, which leads to a Th17/Treg cell imbalance. Research showed that high concentrations of IL-6 in sera and urine samples from SLE patients induced the degradation of Foxp3 and deregulation of Treg cells, possibly indicating a positive correlation with the severity of SLE $[37,38]$. Our previous studies suggested that a Th17/Treg imbalance was observed in the kidneys of LN mice, which resulted in increased levels of IL-6 and IL-17 and decreased concentration of Foxp3 [13]. Thus, our results agreed with previous studies, indicating that the dysregulation of Treg cells is important in the occurrence of renal inflammation and a potential cause of renal damage.

Fractalkine is involved in inflammatory reactions by recruiting immune cells into the inflamed tissues [39, 40]. Recent studies confirmed that Fractalkine is overexpressed and associated with immunological imbalances in LN [41]. Our previous studies indicated that Fractalkine was highly expressed in the serum of SLE patients and kidney tissues of LN mice [1]. Furthermore, in this study, Fractalkine induced the dysfunction of Treg cells and promoted the progression of kidney damage in LN through the P38MAPK signalling pathway.

Apoptosis is the gene-driven pathological process of cell death, which depends on the physiological or pathological conditions, especially in SLE [42]. Apoptosis is generally induced by death receptors, including the Cyt-c, proteaseactivating factor-1, and Bcl-2 protein families [43]. Research showed that the expression of Cyt-c and Bax/Bcl-2 ratio determined the susceptibility of T lymphocytes to apoptosis $[44,45]$. Our results indicated that the downregulation of Fractalkine levels and the inhibition of P38MAPK signalling by SB203580 decreased the expression of Bax and Cyt-C and increased that of $\mathrm{Bcl}-2$, as well as decreased the apoptosis rate of lupus mouse Treg cells. These results confirmed that Fractalkine and p38MAPK played important roles in the apoptosis of Treg cells.

Recently, researchers evidenced that CX3CL1/CX3C chemokine receptor 1 axis played a significant role in the regulation of inflammatory responses through the p38MAPK signalling pathway [46]. In the pathogenesis of acute respiratory distress syndrome, a high Fractalkine expression promoted the phosphorylation of p38MAPK and induced the apoptosis of A549 cells [47]. A previous study determined that autoimmune renal injury and Ig production in MRLFas/Ipr mice were dependent on p38 MAPK activation [48]. In SLE, the specific p38MAPK inhibitor SB203580 blocked T cell apoptosis induced by the anti-CD3 monoclonal antibody [49]. Our data demonstrated that the depletion of Fractalkine and p38MAPK levels promoted the expression of Foxp3 in Treg cells, inhibited the expression of IL-6 and IL-17, and improved renal function. Importantly, depletion of Fractalkine in lupus mouse Treg cells promoted Foxp3 expression and reduced the apoptosis rate of Treg cells by inhibiting p38MAPK. These results suggested that Fractalkine regulated Treg injury and apoptosis by activating the p38MAPK pathway, and promoting the occurrence of LN. 


\section{Conclusion}

Fractalkine downregulated Foxp3 in Treg cells via activation of the p38MAPK signalling pathway, which drived the LN progression. Depletion of Fractalkine and p38MAPK attenuated renal damage in lupus mice by delaying apoptosis. These indings increased the current knowledge of the LN molecular basis and suggested that targeting Fractalkine might be a potential therapeutic strategy for treating $L N$.

\section{Materials And Methods}

\section{Mice}

Eight-week-old female BALB/c mice were purchased from Changsha Tianqin Biotechnology Co., Ltd. (Changsha, China). All mice were housed in the Laboratory animal centre of Youjiang Medical University for Nationalities under controlled conditions: $22-25^{\circ} \mathrm{C}, 40-60 \%$ relative humidity, pathogen-free, a $12 \mathrm{~h}$ light/dark cycle, and ad libitum feeding. Animal Experiments strictly followed the guidelines of the National Institutes of Health and were approved by the Ethical committee of Youjiang Medical University for Nationalities.

Mice were divided into seven groups $(n=5)$ : (1) control group, BALB/c mice (i.p.) received a $500 \mu \mathrm{L}$ intraperitoneal injection of physiological saline solution; (2) lupus group, BALB/c mice received a single $500 \mu \mathrm{L}$ i.p. injection of pristane (\$44062, Shanghai Yuanye Bio-Technology Co., Ltd, China) and was bred for 12 weeks; (3) Fractalkinedepleted group, BALB/c mice were i.p. treated with mouse Fractalkine chemokine domain antibody (MAB571, R\&D Systems, USA, $5.0 \mu \mathrm{g} / \mathrm{mice} /$ day) [50] for 2 weeks; (4) SB203580 group, BALB/c mice were i.p. treated with SB203580 (S1076, Selleck.cn, China, 2 mg/kg/day) [51] for 2 weeks; (5) lupus + Fractalkine-depleted group, lupus mice were i.p. treated with a mouse Fractalkine chemokine domain antibody $(5.0 \mu \mathrm{g} / \mathrm{mice} /$ day $)$ for 2 weeks; (6) lupus + SB203580 group, lupus mice were i.p. injected with SB203580 (2 mg/kg/day) for 2 weeks; (7) lupus + Fractalkine-depleted + SB203580 group, lupus mice were injected with mouse Fractalkine chemokine domain antibody and SB203580, as described above.

Mouse urine samples were collected using metabolic cages for $24 \mathrm{~h}$ to check protein levels, and blood samples and kidney tissues were harvested under anaesthesia with chloral hydrate (400 mg/kg i.p.). Peripheral blood was collected by retro-orbital puncture using heparinised glass capillary tubes (EDTAK2) under sterile conditions, and the serum was separated from the whole blood by centrifugation for $15 \mathrm{~min}$ at $1,000 \times \mathrm{g}$. Serum BUN and creatinine $\mathrm{Cr}$ levels were measured as described previously [52], and the rest of the serum was stored at $-80^{\circ} \mathrm{C}$ for ELISA analysis. Renal tissue samples were fixed with $10 \%$ formalin in $0.01 \mathrm{~mol} / \mathrm{L}$ phosphate buffer $(\mathrm{pH} \mathrm{7.2)}$ overnight, embedded in paraffin for histopathological and immunofluorescence analyses, and the remaining renal tissue was stored at $80^{\circ} \mathrm{C}$ until used for the isolation of total proteins. Aliquots of the renal tissue homogenate $(60 \mathrm{mg} / \mathrm{mL})$ were diluted in RIPA buffer (Beyotime Biotechnology, Shanghai, China) containing a protease inhibitor cocktail (Cwbiotech, Beijing, China) (1:99) and incubated on ice for $30 \mathrm{~min}$, followed by centrifugation at $13,000 \times \mathrm{g}$ for $10 \mathrm{~min}$ at $4{ }^{\circ} \mathrm{C}$. Finally, the supernatants were removed and stored at $-80^{\circ} \mathrm{C}$ for western blot analysis.

\section{Enzyme-linked immunosorbent assay}

The serum concentrations of mouse anti-nuclear, anti-dsDNA, and anti-Sm antibodies were determined using ELISA kits (Cusabio, Houston, TX, USA), according to the manufacturer's instructions. The absorbance at $450 \mathrm{~nm}$ was measured using a TriStar LB 941 multimode microplate reader (Berthold Technologies, Bad Wildbad, Germany).

\section{Histopathological analysis}


To evaluate renal pathological changes, kidney tissue samples were fixed overnight with $10 \%$ formalin in $0.01 \mathrm{~mol} / \mathrm{L}$ phosphate buffer ( $\mathrm{pH} \mathrm{7.2)}$ and then embedded in paraffin for histopathology. Slide sections (3-4 $\mu \mathrm{m}$ thickness) were stained, and examined under a light microscope (BX43, Olympus, Tokyo, Japan. Renal pathology examinations were blindly performed by a pathologist.

\section{Immunofluorescence chemical analysis}

Immunofluorescence stainings of Fractalkine, p-p38, and Foxp3 proteins were performed on $4 \mu \mathrm{m}$-thick paraffinembedded sections of renal tissues after incubation with a primary antibody targeting Fractalkine (DF12376, 1:80; Affinity), Foxp3 (GTX107737, 1:100; GENE TEX), or p-p38 (AF4001, 1:80; Affinity) overnight at $4{ }^{\circ} \mathrm{C}$. Next, the samples were incubated with Alexa Fluor 594-conjugated goat anti-rabbit lgG (H+L) (ZF0516, 1:100; ZSGB-BIO) for $1 \mathrm{~h}$ at $24{ }^{\circ} \mathrm{C}$. Then, the samples were observed with a fluorescence microscope (IX71, Olympus, Tokyo, Japan) equipped with ISC capture software, and the images were collected with a CCD camera (Discovery C15, Olympus, Tokyo, Japan).

\section{Cell culture and transfection}

The spleens of lupus mice were harvested and placed in a Petri dish on a clean workbench. After washing them with normal saline solution, the segments were cut, grounded with a sterile syringe piston, and filtered with a 200-mesh sterile filter. All of the above operations were completed under sterile conditions. The cell filtrate was then collected and centrifuged at $1,500 \times \mathrm{g}$ for $10 \mathrm{~min}$. The centrifuged supernatant was discarded, and $2 \mathrm{~mL}$ of the mixture of red blood cell lysate was added to the cell granules. After allowing the solution to stand for 5 min, the supernatant was centrifuged, and mixed lymphocytes were removed as a precipitate. Then, $10 \mathrm{ng} / \mathrm{mL}$ interleukin-2 (IL-2, 96-212-12-5, Neobioscience, Shenzhen, China) and $10 \mathrm{ng} / \mathrm{mL}$ transforming growth factor- $\beta$ (TGF- $\beta, 100-21-10$, Neobioscience, Shenzhen, China) proteins were added to the cells to induce the proliferation and differentiation of lymphocytes [53]. Following the manufacturer's instructions, $\mathrm{CD} 4^{+} \mathrm{CD} 25^{+}$Treg cells were isolated from lupus mouse spleen lymphocytes by magnetic bead separation. (CD4 ${ }^{+} \mathrm{CD} 25^{+}$regulatory T cell kit; Miltenyi Biotec, Bergisch Gladbach, Germany). In short, non-CD $4^{+} \mathrm{T}$ cells were removed using biotinylated antibody mixtures and anti-biotin microspheres. CD $4^{+} \mathrm{CD} 25^{+}$Treg cells were subsequently separated from $\mathrm{CD} 4^{+} \mathrm{CD} 25^{-}$Treg cells by positive selection using phycoerythrin (PE)-labelled anti-CD25 monoclonal antibodies and anti-PE microbeads and analysed using a FACS Calibur instrument (BD Biosciences). Cells were cultured in RPMI 1640 supplemented with 10\% FBS (Gibco, Waltham, MA, USA) at $37^{\circ} \mathrm{C}$ in a humidified $5 \% \mathrm{CO}_{2}$ atmosphere for later in vitro studies.

Transfection of the cells with Fractalkine siRNA was then conducted. Treg cells were infected with the lentiviral vector particle-Fractalkine (Fractalkine KD) or the hU6-MCS-Ubiquitin-EGFP-IRES-puromycin scramble negative control (negative control), following the manufacturer's instructions (Shanghai Genechem Co. Ltd., China). Cells were then treated with $10 \mu \mathrm{mol} / \mathrm{L}$ SB203580 (S1863-1, Beyotime Biotechnology, China) [54, 55] or 10 nmol/L U-46199 (sc201242, Santa Cruz Biotechnology, Dallas, TX, USA) [27, 56] respectively for $24 \mathrm{~h}$.

\section{Cell apoptosis analysis}

Apoptosis was determined using the fluorescein isothiocyanate (FITC)-Annexin V/propidium iodide (PI) apoptosis kit (FITC-Annexin V/Pl; BD Biosciences). After culturing for $24 \mathrm{~h}$, the cells were centrifuged at $300 \times \mathrm{g}$ for $5 \mathrm{~min}$ at $4{ }^{\circ} \mathrm{C}$. Cells were washed three times with cold PBS, resuspended in $1 \times$ binding buffer at a concentration of $1 \times 10^{6}$ cells $/ \mathrm{mL}$, and incubated with $5 \mu \mathrm{L}$ FITC-Annexin $\mathrm{V}$ and $5 \mu \mathrm{L} \mathrm{PI}$ at $24{ }^{\circ} \mathrm{C}$ in the dark for $15 \mathrm{~min}$, following the 
manufacturer's instructions. Tregs apoptosis was determined by flow cytometry FACSCantoll (BD Biosciences, San Jose, CA, USA) within $1 \mathrm{~h}$.

\section{Quantitative RT-PCR assays}

Following the manufacturer's instructions, total RNA was obtained from the cells by using TRIzol reagent (Invitrogen, Carlsbad, California, USA). Reverse transcriptional synthesis of cDNA was performed from total RNA ( $2 \mu \mathrm{g})$ and using a fastking RT Kit (kr116; Tiangen, Beijing). The expression levels of Foxp3, Bax, Bcl-2, and Cyt-c were detected by quantitative RT-PCR. The primer sequences used for RT-PCR detection are shown in Table 1. RT-PCR was performed using Super Real PreMix Plus (SYBR Green, FP205; Tiangen, Beijing, China), according to the manufacturer's instructions, under the following conditions: $95^{\circ} \mathrm{C}$ for $30 \mathrm{~s}$, followed by 40 cycles of $95^{\circ} \mathrm{C}$ for $10 \mathrm{~s}$ and $65^{\circ} \mathrm{C}$ for $30 \mathrm{~s}$. A total of 81 cycles of $55-95^{\circ} \mathrm{C}$ for $10 \mathrm{~s}$ were performed for melting curve analysis. The amplification of GAPDH cDNA was used as an internal control. Relative gene expression was calculated using the $2^{-\Delta \Delta C t}$ method [57].

Table 1

Primers for qRT-PCR

\begin{tabular}{|lll|}
\hline Name & Forward primer(5'-3') & Reverse primer(5'-3') \\
\hline Foxp3 & ACACCCAGGAAAGACAGCAAC & CGAAGACCTTCTCACAACCAG \\
\hline p38 & CGACCTACTGGAGAAGATGCT & GGTCAGGCTCTTCCACTCAT \\
\hline Bax & GGTTGCCCTCTTCTACTTTGC & GTCCAGCCCATGATGGTTCT \\
\hline Bcl-2 & ATAAGCTGTCACAGAGGGGCTAC & CTCAGGCTGGAAGGAGAAGAT \\
\hline Cyt-C & TTCCCTAACCAGAACCAGACG & CCTGCTTGATCTGCTCATTCC \\
\hline GAPDH & AACTTTGGCATTGTGGAAGG & GGATGCAGGGATGATGTTCT \\
\hline
\end{tabular}

\section{Western blot}

The protein concentrations in mouse renal kidney homogenate and cell lysates were determined using a Bicinchoninic Acid Protein Assay Kit (Beyotime, Shanghai, China). Protein samples were quantified, loaded, and separated by $8 \%$ SDS-PAGE, and then transferred to a PVDF membrane (GE Healthcare, Chicago, IL, USA). Then, the membrane was incubated with $5 \% \mathrm{BSA}$ for $1 \mathrm{~h}$ at $24{ }^{\circ} \mathrm{C}$ to block the unspecific binding of antibodies. Then, the membranes were incubated with primary antibodies targeting Fractalkine (DF12376, 1:800; Affinity), Foxp3 (GTX107737, 1:1000; GENE TEX), p-p38MAPK (AF4001, 1:800; Affinity), p38MAPK (ab170099, 1:800; Abcam), IL-6 (DF6087, 1:800; Affinity), IL-17 (DF6127, 1:800; Affinity), Bax (AF0120, 1:1000; Affinity), Bcl-2 (AF6139, 1:800; Affinity), Cyt-c (bs-0013R, 1:800; Bioss), and GAPDH (Bs-2188R, 1:1000; BIOSS) at $4{ }^{\circ} \mathrm{C}$ overnight. The membrane was washed three times with TBST before incubation with the secondary antibody Goat Anti-mouse IgG (S0002, 1:2000; Affinity) and Goat Anti-Rabbit IgG (S0001, 1:2000; Affinity). In order to detect the proteins, immunoblotting was performed with an enhanced chemiluminescence western blot detection kit (Millipore, Billerica, MA, USA). The immunoreactive bands were visualised using an ECL advance kit (Lot: sc-2048, ZSGB-BIO) and their intensities were quantified by densitometry with Image $\mathrm{J}$ software. Bovine serum albumin (BSA) was used as a standard protein.

Table 2: Mean optical density 


\begin{tabular}{|llllllll|}
\hline & Control & Lupus & $\begin{array}{l}\text { Fractalkine- } \\
\text { depleted }\end{array}$ & SB203580 & $\begin{array}{l}\text { Lupus + } \\
\text { Fractalkine- } \\
\text { depleted }\end{array}$ & $\begin{array}{l}\text { Lupus + } \\
\text { SB203580 }\end{array}$ & $\begin{array}{l}\text { Fupus + } \\
\text { Fractalkine- } \\
\text { depleted + }\end{array}$ \\
Fractalkine & $0.40 \pm 0.01^{*}$ & $0.77 \pm 0.01^{\#}$ & $0.35 \pm 0.01^{*}$ & $0.33 \pm 0.02^{*}$ & $0.65 \pm 0.02^{\&}$ & $0.48 \pm 0.06^{\&}$ & $0.27 \pm 0.01$ \\
\hline p-p38 & $0.29 \pm 0.08^{*}$ & $0.60 \pm 0.02^{\#}$ & $0.23 \pm 0.03^{*}$ & $0.22 \pm 0.04^{*}$ & $0.46 \pm 0.01^{\&}$ & $0.44 \pm 0.00^{\&}$ & $0.10 \pm 0.02$ \\
\hline Foxp3 & $0.14 \pm 0.00^{*}$ & $0.02 \pm 0.01^{\#}$ & $0.13 \pm 0.00^{*}$ & $0.13 \pm 0.00^{*}$ & $0.08 \pm 0.13^{\&}$ & $0.07 \pm 0.01^{\&}$ & $0.17 \pm 0.05$ \\
\hline
\end{tabular}

${ }^{*} p<0.05$, when compared with lupus group; ${ }^{*} p<0.05$, when compared with lupus + Fractalkine-depleted group; ${ }^{\#} p<0.05$, when compared with lupus + SB203580 group; ${ }^{\&} p<0.05$, compared with lupus + Fractalkine-depleted + SB203580 group.

\section{Statistical analysis}

The final data are expressed as the mean \pm standard deviation of three or more experiments. One-way analysis of variance and Student's t-test (t-test) were used to analyse groups and independent samples, respectively. All analyses were conducted using SPSS 23.0 software (SPSS Inc., Chicago, IL, USA). A value of $p<0.05$ was considered statistically significant.

\section{Declarations}

\section{Ethics approval and consent to participate}

Animal Experiments strictly followed the guidelines of the National Institutes of Health and were approved by the Ethical committee of Youjiang Medical University for Nationalities.

\section{Funding}

This research was supported by the National Natural Science Foundation of China (Grants 81560271 and 81860296 ), the Natural Science Foundation of Guangxi (Grants 2017GXNSFDA198005 and 2018GXNSFAA281038), the Innovation Project of Guangxi Graduate Education (Grant YCSW2019221), and the Key Laboratory Project of Guangxi Colleges and Universities (Grant KFKT20160051).

\section{Competing Interest}

The authors declare that they have no competing interests.

\section{Data Availability Statement}

The dataset supporting the conclusions of this article is included within the article.

\section{Consent for publication}

Not applicable.

\section{Authors' contributions}


Jingxue Ma, Qiming Gong, and Pengwei Guo carried out the experimental work and conceived of the study and participated in its design and coordination. Xiuhong Pan and Linlin He participated in the design of the study and together with Yanwu You performed the statistical analysis. Jingxue Ma and Yanwu You drafted the manuscript. All authors read and approved the final manuscript. Jingxue Ma, Qiming Gong, and Pengwei Guo are co-first authors.

\section{Acknowledgements}

The authors would like to thank Editage (www.editage.cn) for English language editing.

\section{References}

1. Fernández-Nebro A, Marsal S, Chatham W, Rahman A. Systemic Lupus Erythematosus: Genomics, Mechanisms, and Therapies. Clin Dev Immunol 2012, 2012:926931.

2. You Y, Qin Y, Lin X, Yang F, Wang J, Yuan F, et al. Upregulated fractalkine levels in Chinese patients with lupus nephritis. Cytokine. 2018;104:23-8.

3. Yu SL, Kuan WP, Wong CK, Li EK, Tam LS. Immunopathological roles of cytokines, chemokines, signaling molecules, and pattern-recognition receptors in systemic lupus erythematosus. Clin Dev Immunol. 2012;2012:715190.

4. Madelung C, Krüger Falk M, Sørensen TL. The association between neovascular age-related macular degeneration and regulatory T cells in peripheral blood. Clin Ophthalmol. 2015;9:1147-54.

5. Kuhn A, Beissert S, Krammer PH. CD4 + CD25 + regulatory T cells in human lupus erythematosus. Arch Dermatol Res. 2009;301(1):71-81.

6. Sakaguchi S. The origin of FOXP3-expressing CD4 + regulatory T cells: thymus or periphery. J Clin Invest. 2003;112(9):1310-12.

7. Fontenot JD, Gavin MA, Rudensky AY. Foxp3 programs the development and function of CD4 + CD25+ regulatory T cells. Nat Immunol. 2003;4(4):330-6.

8. Bacchetta R, Passerini L, Gambineri E, Dai M, Allan SE, Perroni L, et al. Defective regulatory and effector T cell functions in patients with FOXP3 mutations. J Clin Invest. 2006;116(6):1713-22.

9. Sakaguchi S, Yamaguchi T, Nomura T, Ono M. Regulatory T cells and immune tolerance. Cell.2008, 133(5):77587.

10. Tang TT, Zhu ZF, Wang J, Zhang WC, Tu X, Xiao H, et al. Impaired thymic export and apoptosis contribute to regulatory T-cell defects in patients with chronic heart failure. PloS one. 2011;6(9):e24272.

11. Kim JM, Rasmussen JP, Rudensky AY. Regulatory T cells prevent catastrophic autoimmunity throughout the lifespan of mice. Nat Immunol. 2007;8(2):191-7.

12. Komatsu N, Okamoto K, Sawa S, Nakashima T, Oh-hora M, Kodama T, et al. Pathogenic conversion of Foxp3 + T cells into TH17 cells in autoimmune arthritis. Nat Med. 2014;20(1):62-8.

13. Fu D, Senouthai S, Wang J, You Y. Vasoactive intestinal peptide ameliorates renal injury in a pristane-induced lupus mouse model by modulating Th17/Treg balance. BMC Nephrol. 2019;20(1):350.

14. Zheng Y, Rudensky AY. Foxp3 in control of the regulatory T cell lineage. Nat Immunol. 2007;8(5):457-62.

15. Valencia X, Yarboro C, Illei G, Lipsky PE. Deficient CD4 + CD25high T Regulatory Cell Function in Patients with Active Systemic Lupus Erythematosus. J Immunol. 2007;178(4):2579-88.

16. Ruchaya PJ, Antunes VR, Paton JF, Murphy D, Yao ST. The cardiovascular actions of fractalkine/CX3CL1 in the hypothalamic paraventricular nucleus are attenuated in rats with heart failure. Exp Physiol. 2014;99(1):111-22.

Page $11 / 24$ 
17. Imai T, Yasuda N. Therapeutic intervention of inflammatory/immune diseases by inhibition of the fractalkine (CX3CL1)-CX3CR1 pathway. Inflamm Regen. 2016;36:9.

18. Wolf M, Albrecht S, Marki C. Proteolytic processing of chemokines: implications in physiological and pathological conditions. Int J Biochem Cell Biol. 2008;40(6-7):1185-98.

19. Hamann I, Unterwalder N, Cardona AE, Meisel C, Zipp F, Ransohoff RM, et al. Analyses of phenotypic and functional characteristics of CX3CR1-expressing natural killer cells. Immunology. 2011;133(1):62-73.

20. Kobayashi T, Okamoto S, Iwakami Y, Nakazawa A, Hisamatsu T, Chinen H, et al. Exclusive increase of CX3CR1 + CD28-CD4 + T cells in inflammatory bowel disease and their recruitment as intraepithelial lymphocytes. Inflamm Bowel Dis. 2007;13(7):837-46.

21. Ancuta P, Rao R, Moses A, Mehle A, Shaw SK, Luscinskas FW. Get al. Fractalkine preferentially mediates arrest and migration of CD16 + monocytes. J Exp Med. 2003;197(12):1701-7.

22. El-Shazly A, Berger P, Girodet PO, Ousova O, Fayon M, Vernejoux JM, et al. Fraktalkine produced by airway smooth muscle cells contributes to mast cell recruitment in asthma. J Immunol. 2006;176(3):1860-8.

23. Lyszkiewicz M, Witzlau K, Pommerencke J, Krueger A. Chemokine receptor CX3CR1 promotes dendritic cell development under steady-state conditions. Eur J Immunol. 2011;41(5):1256-65.

24. You Y, Qin Y, Lin X, Yang F, Li J, Sooranna SR, et al. Methylprednisolone attenuates lipopolysaccharide-induced Fractalkine expression in kidney of Lupus-prone MRL/Ipr mice through the NF-kappaB pathway. BMC Nephrol. 2015;16:148.

25. Senouthai S, Wang J, Fu D, You Y. Fractalkine is Involved in Lipopolysaccharide-Induced Podocyte Injury through the Wnt/beta-Catenin Pathway in an Acute Kidney Injury Mouse Model. Inflammation. 2019;42(4):1287-300.

26. Zhou E, Li Y, Wei Z, Fu Y, Lei H, Zhang N, et al. Schisantherin A protects lipopolysaccharide-induced acute respiratory distress syndrome in mice through inhibiting NF-KB and MAPKs signaling pathways. Int Immunopharmacol. 2014;22(1):133-40.

27. Iwata Y, Wada T, Furuichi K, Sakai N, Matsushima K, Yokoyama H, et al. p38 Mitogen-Activated Protein Kinase Contributes to Autoimmune Renal Injury in MRL-Faslpr Mice. J Am Soc Nephrol. 2003;14(1):57-67.

28. Cuenda A, Rousseau S. p38 MAP-kinases pathway regulation, function and role in human diseases. Biochim Biophys Acta. 2007;1773(8):1358-75.

29. Sumida T, Otani H, Kyoi S, Okada T, Imamura H. Temporary blockade of contractility during reperfusion elicits a cardioprotective effect of the p38 MAP kinase inhibitor SB-203580. AJP Heart Cir Physiol. 2005;288(6):H272634.

30. Kang X, Jing M, Zhang G, He L, Hong P, Deng C. The Ameliorating Effect of Plasma Protein from Tachypleus tridentatus on Cyclophosphamide-Induced Acute Kidney Injury in Mice. Mar Drugs. 2019;15(17(4):227.

31. Liu Y, Deng W, Meng Q, Qiu X, Sun D, Dai C. CD8 + iTregs attenuate glomerular endothelial cell injury in lupusprone mice through blocking the activation of p38 MAPK and NF-KB. Mol Immunol. 103:133-43.

32. Zhi-Chun L, Qiao-Ling Z, Zhi-Qin L, Xiao-Zhao L, Xiao-xia Z, Rong T. Tumor Necrosis Factor-Like Weak Inducer of Apoptosis (TWEAK) Mediates p38 Mitogen-Activated Protein Kinase Activation and Signal Transduction in Peripheral Blood Mononuclear Cells from Patients with Lupus Nephritis. Inflammation. 2012;35(3):935-43.

33. Liu Z, Xue L, Liu Z, Huang J, Wen J, Hu J, et al. Tumor Necrosis Factor-Like Weak Inducer of Apoptosis Accelerates the Progression of Renal Fibrosis in Lupus Nephritis by Activating SMAD and p38 MAPK in TGF. Mediators Inflamm. 2016, 2016:8986451.

34. Senouthai S, Wang J, Fu D, You Y. Fractalkine is Involved in Lipopolysaccharide-Induced Podocyte Injury through the Wnt/ $\beta$-Catenin Pathway in an Acute Kidney Injury Mouse Model. Inflammation. 2019;42(4):1287-300. 
35. Jin N, Wang Q, Zhang X, Jiang D, Cheng H, Zhu K. The selective p38 mitogen-activated protein kinase inhibitor, SB203580, improves renal disease in MRL/Ipr mouse model of systemic lupus. Int Immunopharmacol. 2011;11(9):1319-26.

36. You Y, Qin Y, Lin X, Yang F, Li J, Sooranna SR, et al. Methylprednisolone attenuates lipopolysaccharide-induced Fractalkine expression in kidney of Lupus-prone MRL/Ipr mice through the NF-kappaB pathway. BMC Nephrol. 2015;16:148.

37. Dong L, Nordlohne J, Ge S, Hertel B, Melk A, Rong S, et al. T Cell CX3CR1 Mediates Excess Atherosclerotic Inflammation in Renal Impairment. J Am Soc Nephrol. 2016;27(6):1753-64.

38. El Zein N, Abdallah MS, Daher CF, Mroueh M, Stephan J, Bahous SA, et al. Ghrelin modulates intracellular signalling pathways that are critical for podocyte survival. Cell Biochem Funct. 2019;37(4):245-55.

39. Li W, Geng L, Liu X, Gui W, Qi H. Recombinant adiponectin alleviates abortion in mice by regulating Th17/Treg imbalance via p38MAPK-STAT5 pathway. Biol Reprod. 2019;1(4):1008-17. 100(.

40. Tsujimoto M, Doi T, Kuroyanagi G, Yamamoto N, Matsushima-Nishiwaki R, lida Y, et al. aB-crystallin reduces ristocetin? induced soluble CD40 ligand release in human platelets: Suppression of thromboxane A2 generation. Mol Med Rep. 2015;12(1):357-62.

41. Feng X, Liu P, Zhou X, Li M-T, Li F-L, Wang Z, et al. Thromboxane A2 Activates YAP/TAZ Protein to Induce Vascular Smooth Muscle Cell Proliferation and Migration. J Biol Chem. 2016;291(36):18947-58.

42. Schmittgen TD, Livak J. Analyzing real-time PCR data by comparative CT method. Nat Protoc. 2008;3(6):1101-8.

43. Freitas EC, de Oliveira MS, Monticielo OA. Pristane-induced lupus: considerations on this experimental model. Clin Rheumatol. 2017;36(11):2403-14.

44. Chae BS, Shin TY. Immunoregulatory abnormalities of T cells and hyperreactivity of B cells in the In Vitro immune response in pristane-induced lupus mice. Arch Pharm Res. 2007;30(2):191-8.

45. Sakaguchi S. Naturally arising CD 4 + regulatory t cells for immunologic self-tolerance and negative control of immune responses. Annu Rev Immunol. 2004;22:531-62.

46. Linker-Israeli M, Deans RJ, Wallace DJ, Prehn J, Klinenberg JR. Elevated levels of endogenous IL-6 in systemic lupus Erythematosus. J Immunol. 1991;147(1):117-23.

47. Sabry A, Elbasyouni SR, Sheashaa HA, Alhusseini AA, Mahmoud K, George SK, et al. Correlation between levels of TNF- $a$ and IL-6 and hematological involvement in SLE Egyptian Patients with lupus nephritis. Int Urol Nephrol. 2006;38(3-4):731-7.

48. Fu D, Senouthai S, Wang J, You Y. FKN Facilitates. HK-2 Cell EMT and Tubulointerstitial Lesions via the Wnt/betaCatenin Pathway in a Murine Model of Lupus Nephritis. Front Immunol. 2019;10:784.

49. Senouthai S, Wang J, Fu D, You Y. Fractalkine is Involved in Lipopolysaccharide-Induced Podocyte Injury through the Wnt/beta-Catenin Pathway in an Acute Kidney Injury Mouse Model. Inflammation. 2019;42(4):1287-300.

50. Nanki T, Imai T, Kawai S. Fractalkine/CX3CL1 in rheumatoid arthritis. Mod Rheumatol. 2017;27(3):392-7.

51. Ruggieri M, Avolio C, Scacco S, Pica C, Lia A, Zimatore GB, et al. Glatiramer acetate induces pro-apoptotic mechanisms involving Bcl-2, Bax and Cyt-c in peripheral lymphocytes from multiple sclerosis patients. J Neurol. 2006;253(2):231-6.

52. Green DR, Reed JC. Mitochondria and apoptosis. Science. 1998;281(5381):1309-12.

53. Krammer PH. CD95's deadly mission in the immune system. Nature. 2000;407(6805):789-95.

54. Rathmell JC, Thompson CB. The central effectors of cell death in the immune system. Annu Rev Immunol. 1999;17:781-828.

Page $13 / 24$ 
55. Wu X, Liu Y, Qian Z, Luo Q, Ke Y. CX3CL1/CX3CR1 Axis Plays a Key Role in Ischemia-Induced Oligodendrocyte Injury via p38MAPK Signaling Pathway. Mol Neurobiol. 2016;53(6):4010-8.

56. Xia H, Yi Z, Jiang Y, Qin Y, Luo W, Xiang S, et al. Lipopolysaccharide-Binding Protein Downregulates Fractalkine through Activation of p38 MAPK and NF-kB. Mediators Inflamm. 2017, 2017: 9734837.

57. Zhang J, Gao JX, Salojin K, Shao Q, Grattan M, Meagher C, et al. Regulation of FAS Ligand Expression during Activation-Induced Cell Death in T Cells by p38 Mitogen-Activated Protein Kinase and C-Jun Nh2-Terminal Kinase. J Exp Med. 2000;191(6):1017-30.

\section{Figures}
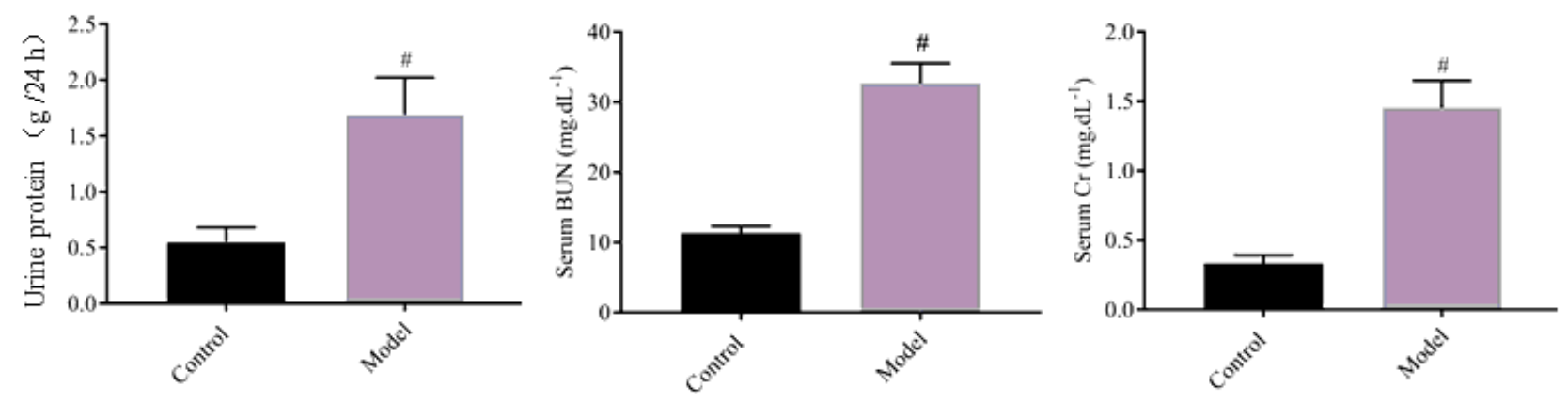

(a)

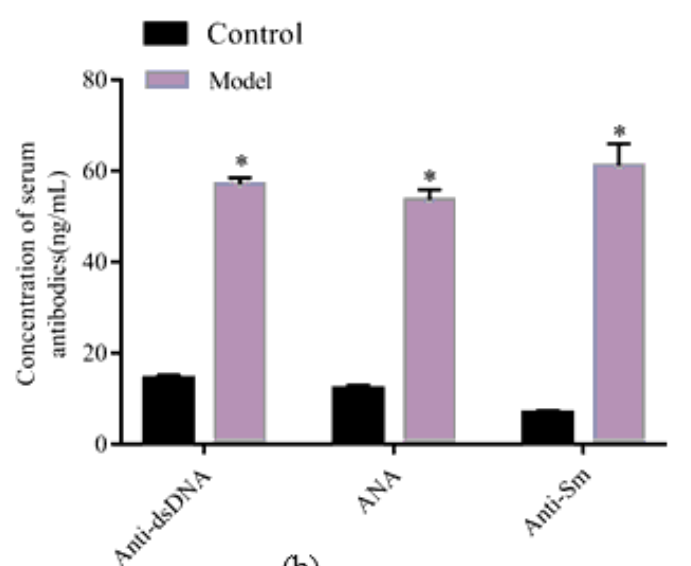

(b)

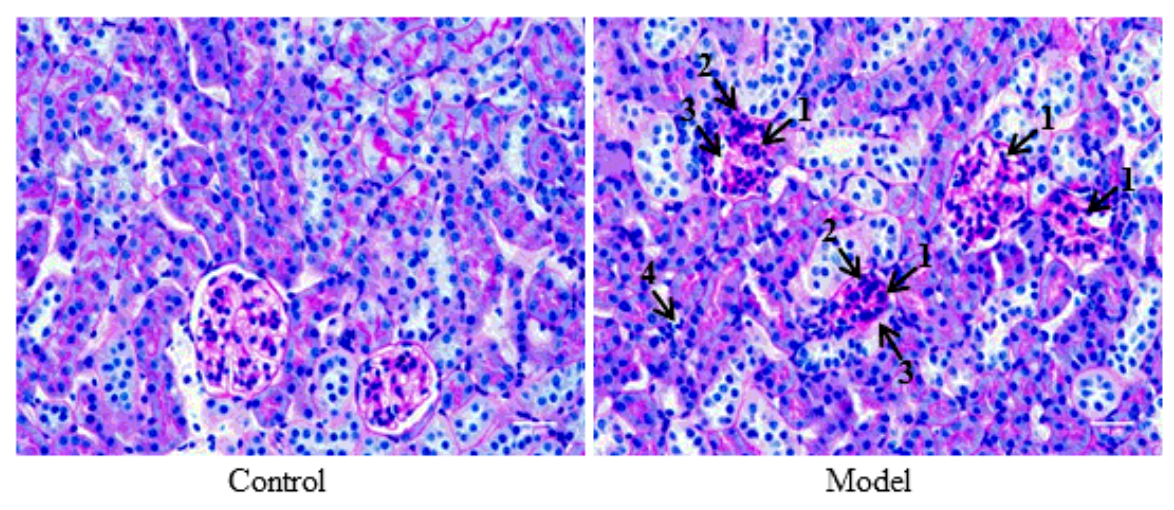

(c)

\section{Figure 1}

Establishment of the LN mouse model (a) Levels of urine protein and of serum $\mathrm{Cr}$ and BUN in mice. \#p $<0.05$ vs. control group. (b) Expression of the anti-nuclear antibodies: ANA, anti-dsDNA, and anti-Sm in the serum of the LN and control groups. ${ }^{*} p<0.05$ vs. control group. All data are presented as the mean $\pm S D$ of three independent experiments performed in triplicate. (c) Histopathological features of mouse renal tissues determined by Periodic SchiffMethenamine (original magnification, $\times 400$ ). 

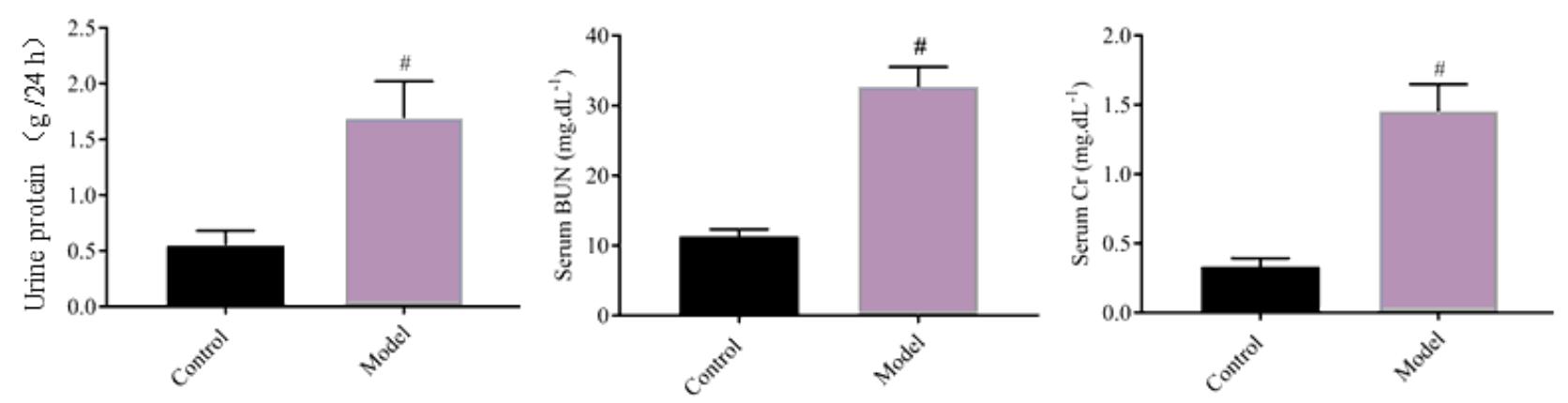

(a)

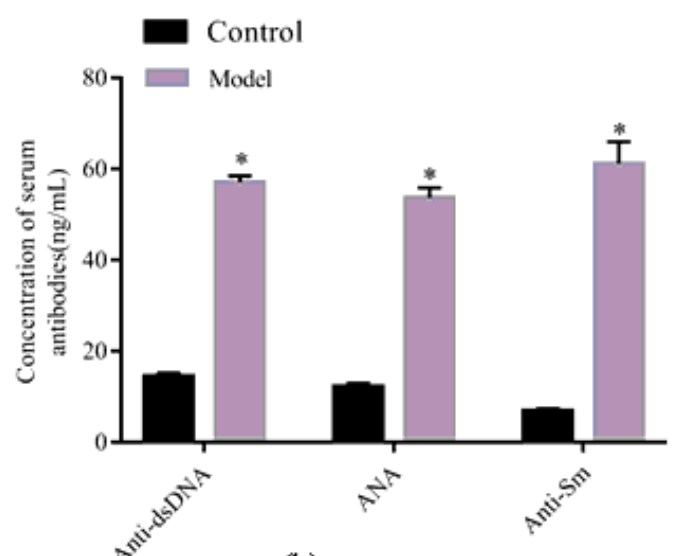

(b)

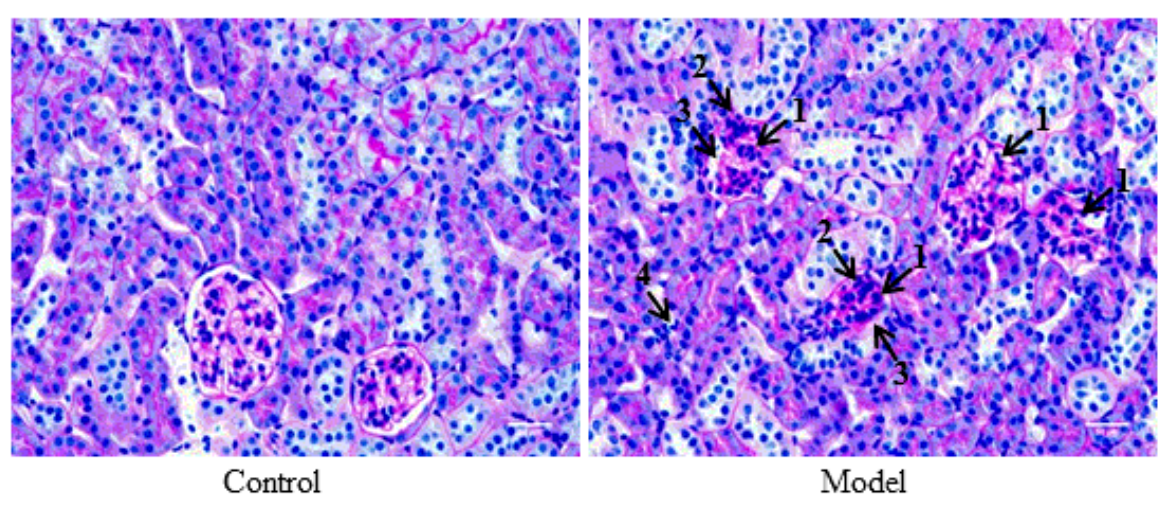

(c)

Figure 1

Establishment of the LN mouse model (a) Levels of urine protein and of serum $\mathrm{Cr}$ and BUN in mice. \#p $<0.05$ vs. control group. (b) Expression of the anti-nuclear antibodies: ANA, anti-dsDNA, and anti-Sm in the serum of the LN and control groups. ${ }^{*} p<0.05$ vs. control group. All data are presented as the mean \pm SD of three independent experiments performed in triplicate. (c) Histopathological features of mouse renal tissues determined by Periodic SchiffMethenamine (original magnification, $\times 400$ ). 


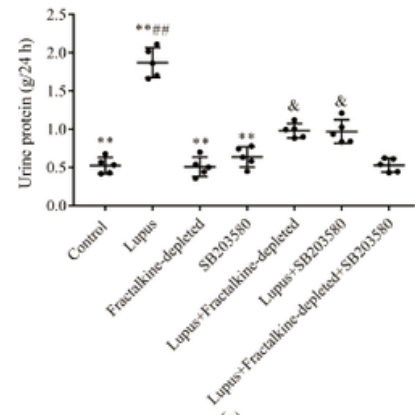

(a)

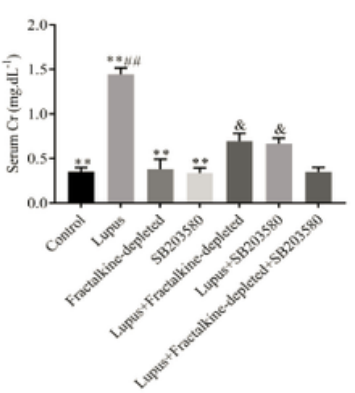

(b)

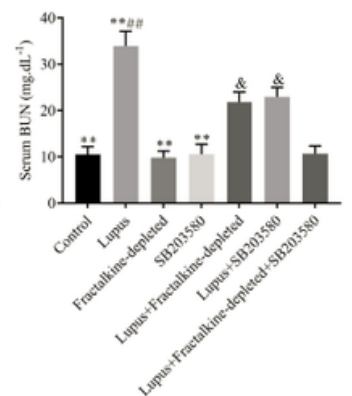

(c)

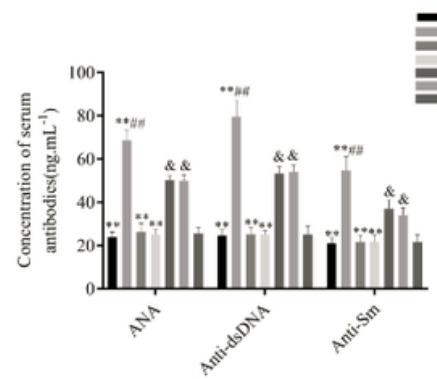

(d)

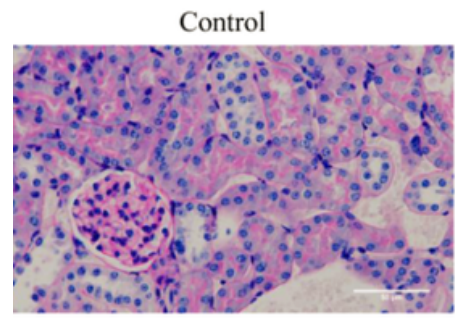

Lupus+Fractalkine-depleted

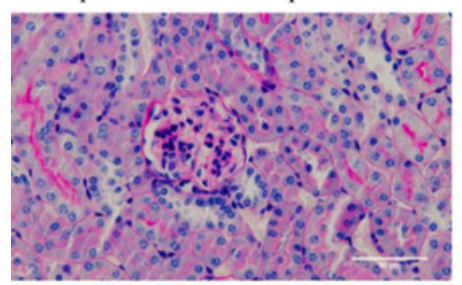

Lupus

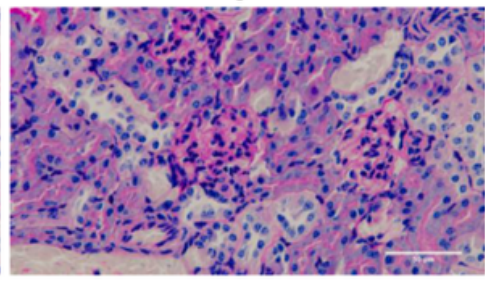

Lupus+SB203580

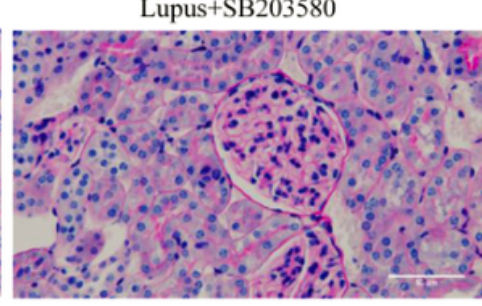

Fractalkine-depleted

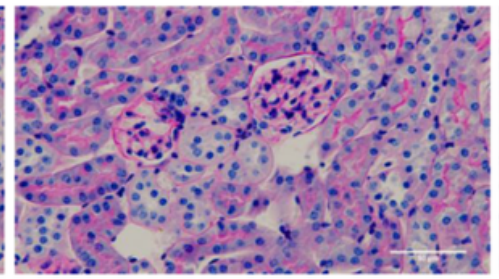

Lupus+Fractalkine-depleted+SB203580

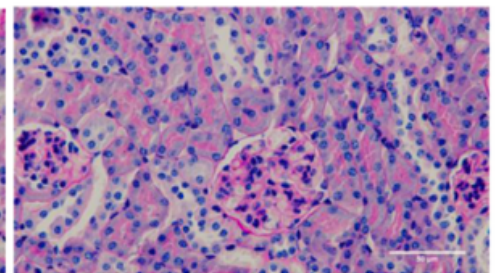

SB203580

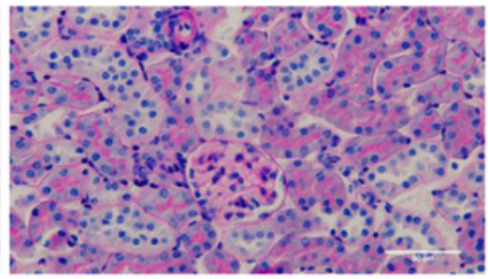

(e)

\section{Figure 2}

Decreased serum levels of autoantibody, function, and kidney structural damage in lupus mice by inhibitors of Fractalkine and the p38MAPK pathway $(\mathrm{a}-\mathrm{d})$ Assessment of kidney function and serum levels of $\mathrm{Cr}$, BUN, and autoantibodies in mice. (e) Histological findings in renal tissues from the seven experimental groups. ${ }^{\star *} \mathrm{p}<0.05$ vs. lupus mice; $* \star \# \# p<0.05$ vs. lupus mice + Fractalkine-depleted; $* \star \# \# p<0.05$ vs. lupus mice + SB203580; \&p $<0.05$ vs. lupus + Fractalkine-depleted + SB203580 mice. 


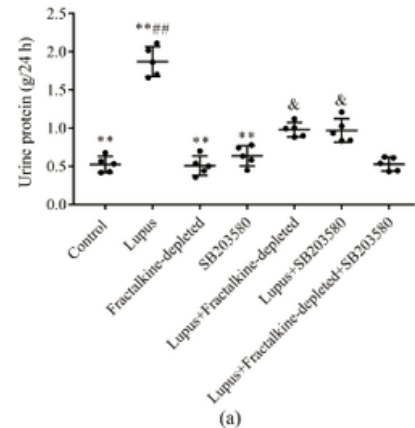

(a)

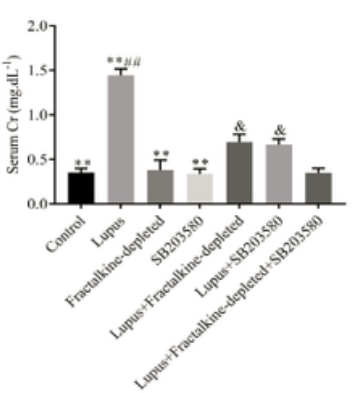

(b)

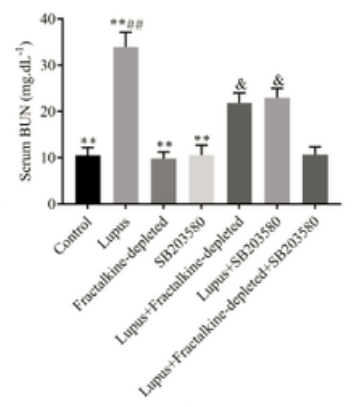

(c)

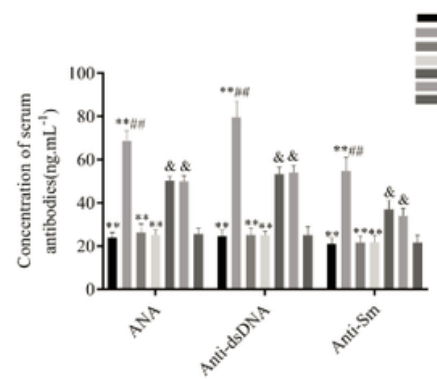

(d)

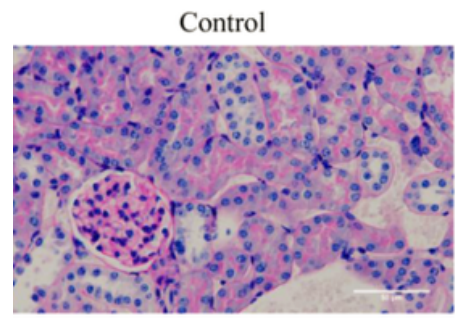

Lupus+Fractalkine-depleted

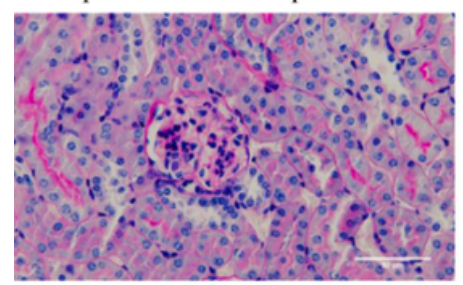

Lupus

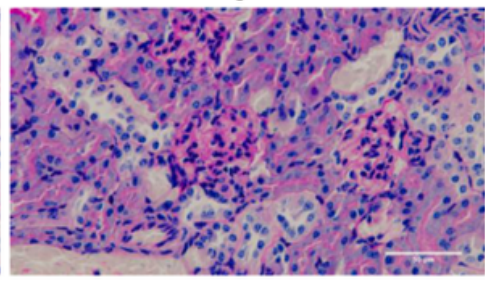

Lupus+SB203580

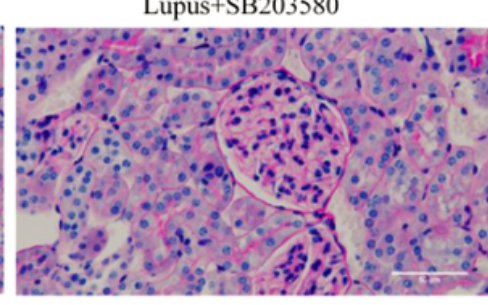

Fractalkine-depleted

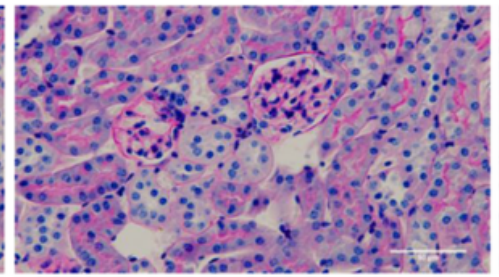

Lupus+Fractalkine-depleted+SB203580

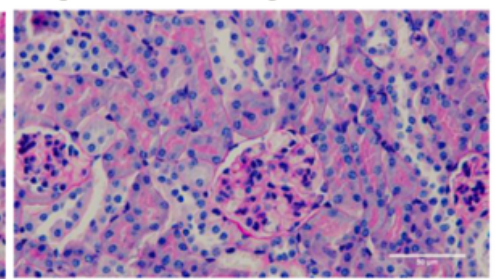

(e)

\section{Figure 2}

Decreased serum levels of autoantibody, function, and kidney structural damage in lupus mice by inhibitors of Fractalkine and the p38MAPK pathway $(\mathrm{a}-\mathrm{d})$ Assessment of kidney function and serum levels of $\mathrm{Cr}$, BUN, and autoantibodies in mice. (e) Histological findings in renal tissues from the seven experimental groups. ${ }^{* \star} p<0.05$ vs. lupus mice; $* \star \# \# p<0.05$ vs. lupus mice + Fractalkine-depleted; $* \star \# \# p<0.05$ vs. lupus mice + SB203580; \&p $<0.05$ vs. lupus + Fractalkine-depleted + SB203580 mice. 


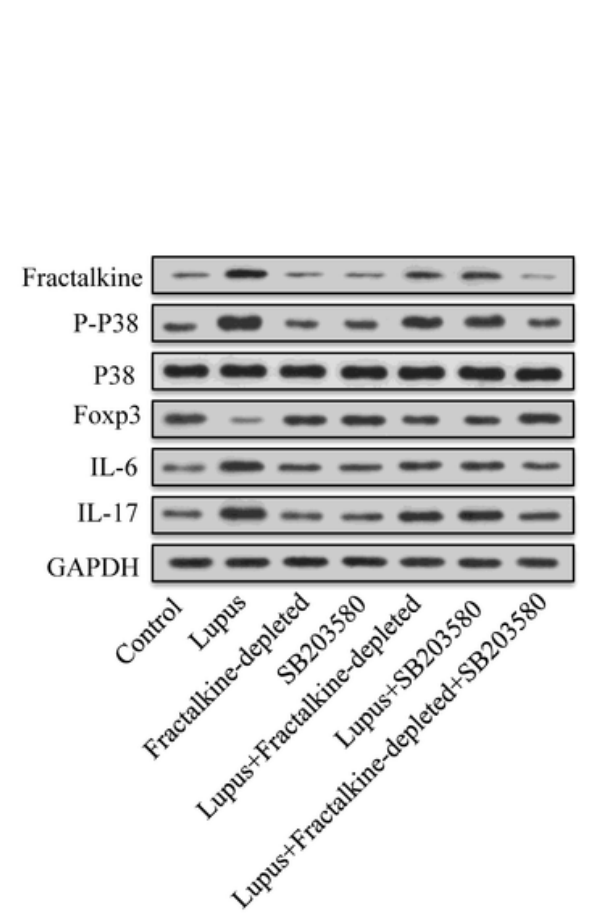

(a)

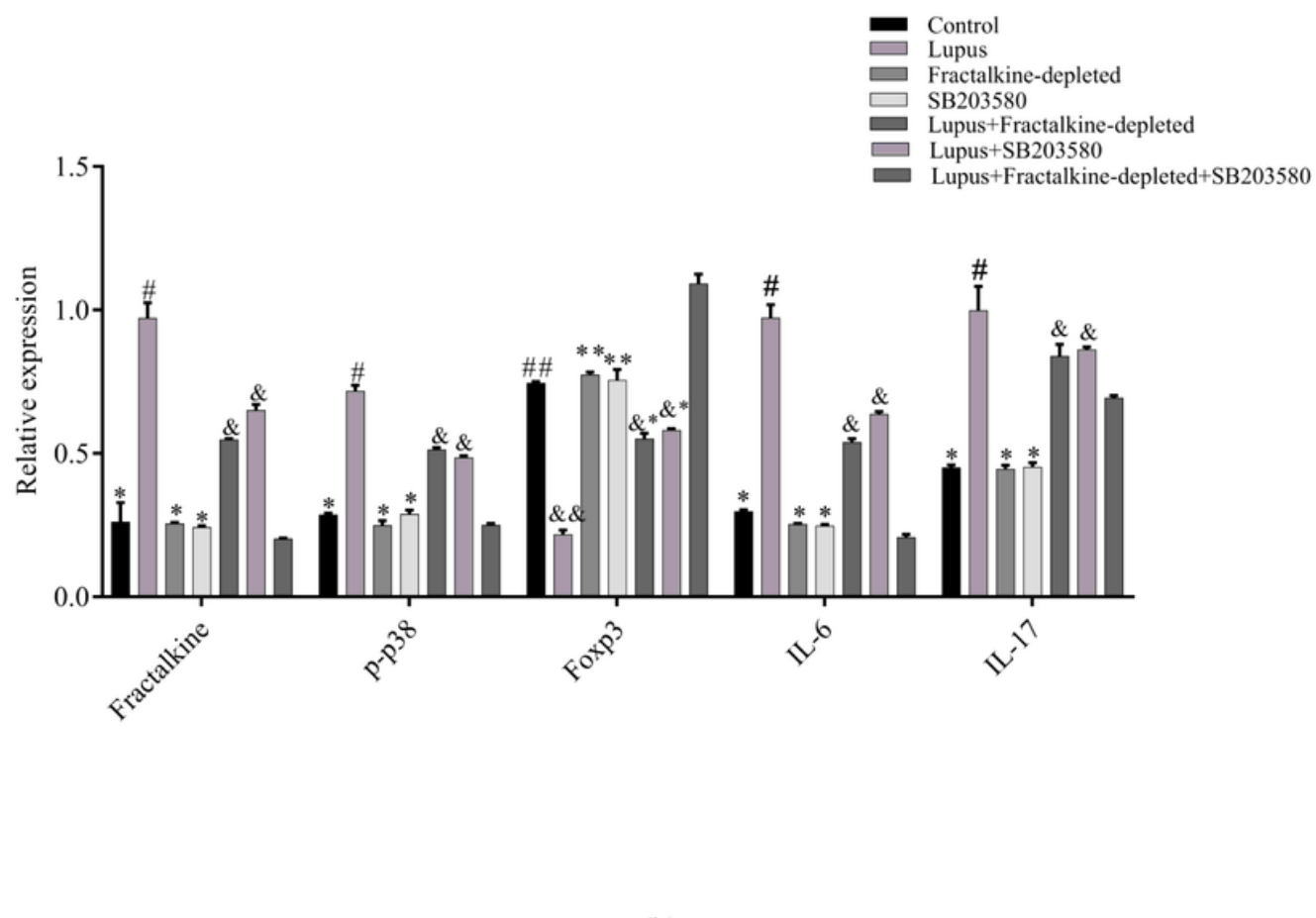

(b)

\section{Figure 3}

Protein expression of Fractalkine, p-p38, p38, Foxp3, IL-6, and IL-17 in renal mouse tissue (a) Expression of these proteins in renal mouse tissue. (b) * $p<0.05$, \#\#p $<0.05$ vs. lupus mice; $p<0.05, \# p<0.05, \& \& p<0.05$ vs. lupus + Fractalkine-depleted mice; $p<0.05, \# p<0.05, \& \& p<0.05$ vs. lupus + SB203580 mice; \&p $<0.05, \& \&^{*}<0.05$ vs. lupus + Fractalkine-depleted + SB203580 mice.

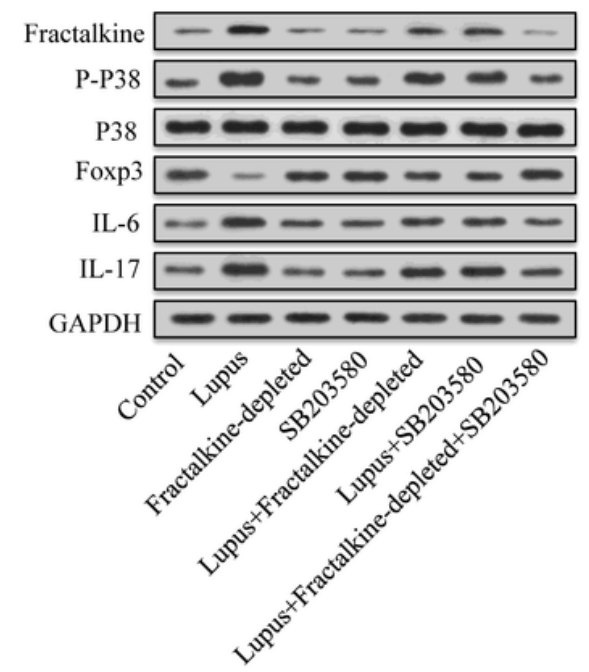

(a)

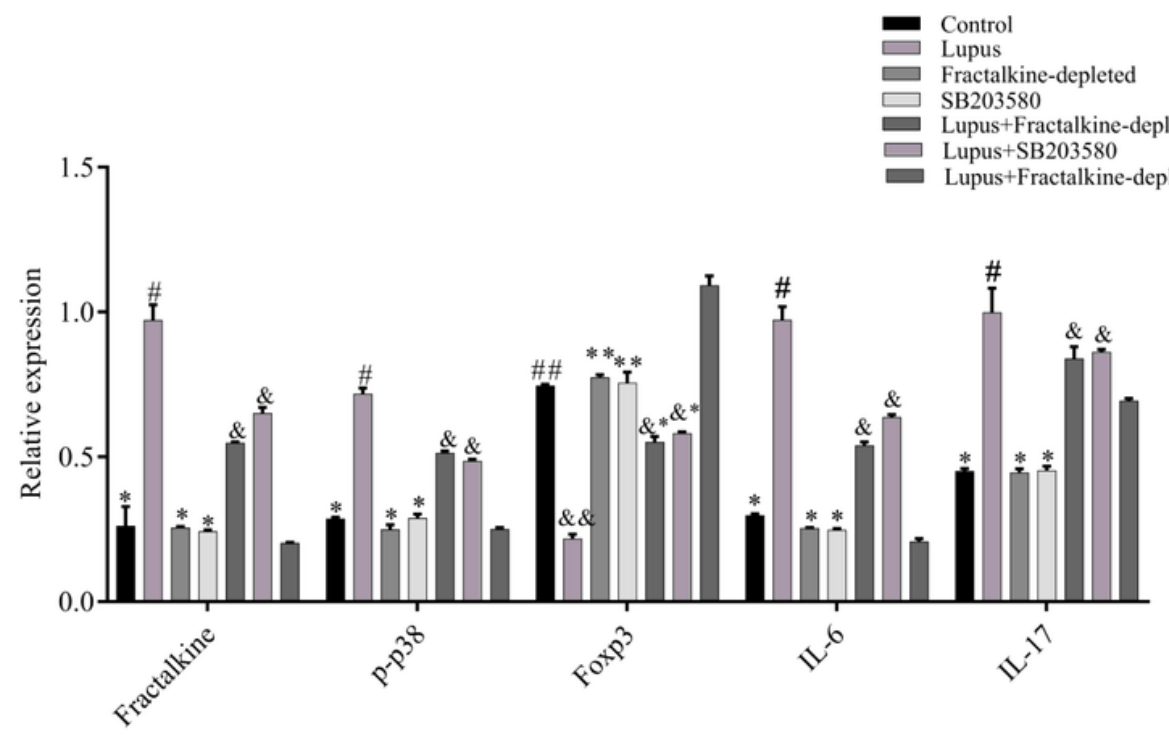

\section{Figure 3}


Protein expression of Fractalkine, p-p38, p38, Foxp3, IL-6, and IL-17 in renal mouse tissue (a) Expression of these proteins in renal mouse tissue. (b) * $p<0.05$, \#\#p $<0.05$ vs. lupus mice; $p<0.05, \# p<0.05, \& \& p<0.05$ vs. lupus + Fractalkine-depleted mice; $p<0.05, \# p<0.05, \& \& p<0.05$ vs. lupus $+S B 203580$ mice; $\& p<0.05, \& *^{*}<0.05$ vs. lupus + Fractalkine-depleted + SB203580 mice.
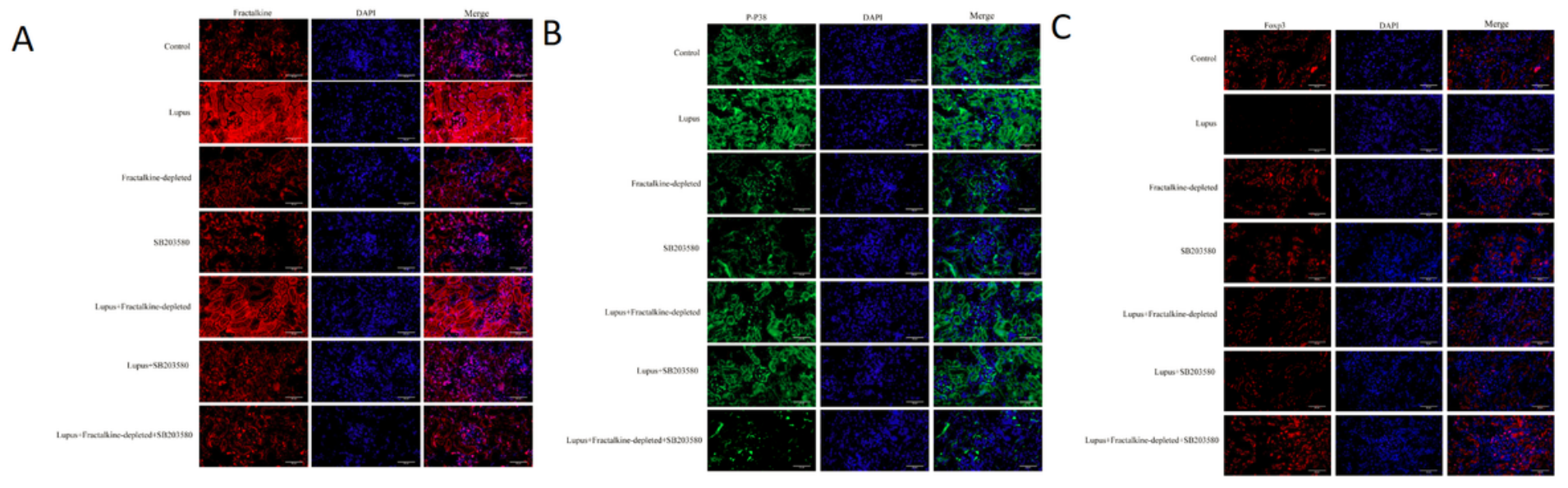

\section{Figure 4}

Expression of Fractalkine, p-p38, and Foxp3 proteins in mouse kidneys Renal tissue sections of mice were stained by immunofluorescence (original magnification, 400). (a) Fractalkine; (b) p-p38; (c) Foxp3.
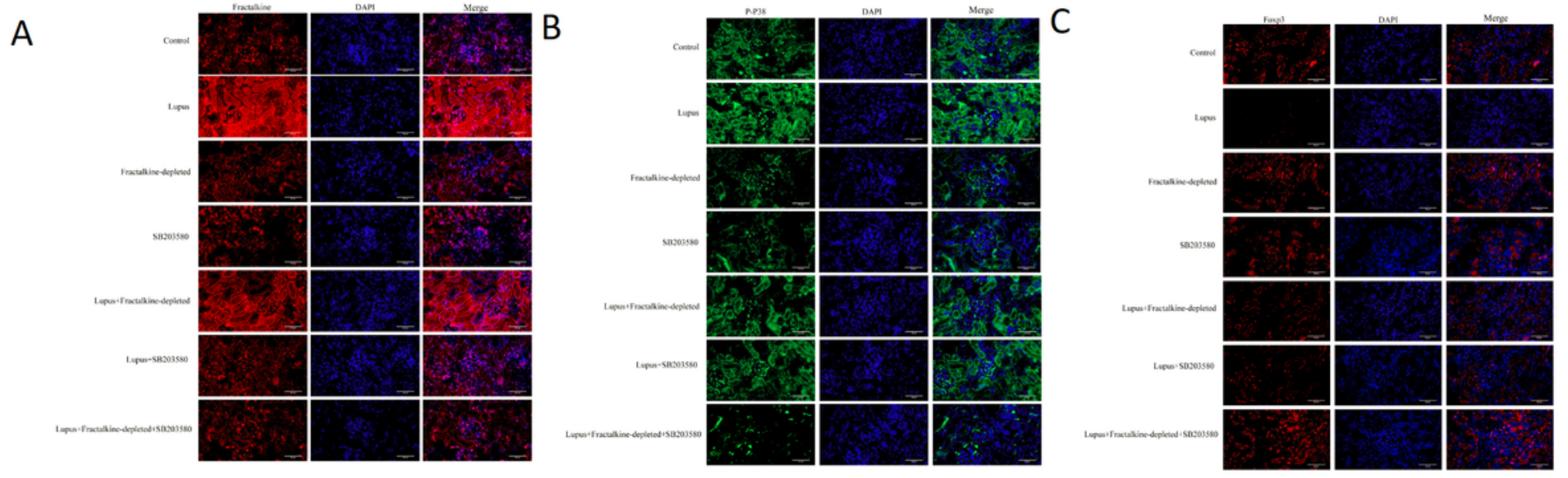

\section{Figure 4}

Expression of Fractalkine, p-p38, and Foxp3 proteins in mouse kidneys Renal tissue sections of mice were stained by immunofluorescence (original magnification, 400). (a) Fractalkine; (b) p-p38; (c) Foxp3. 

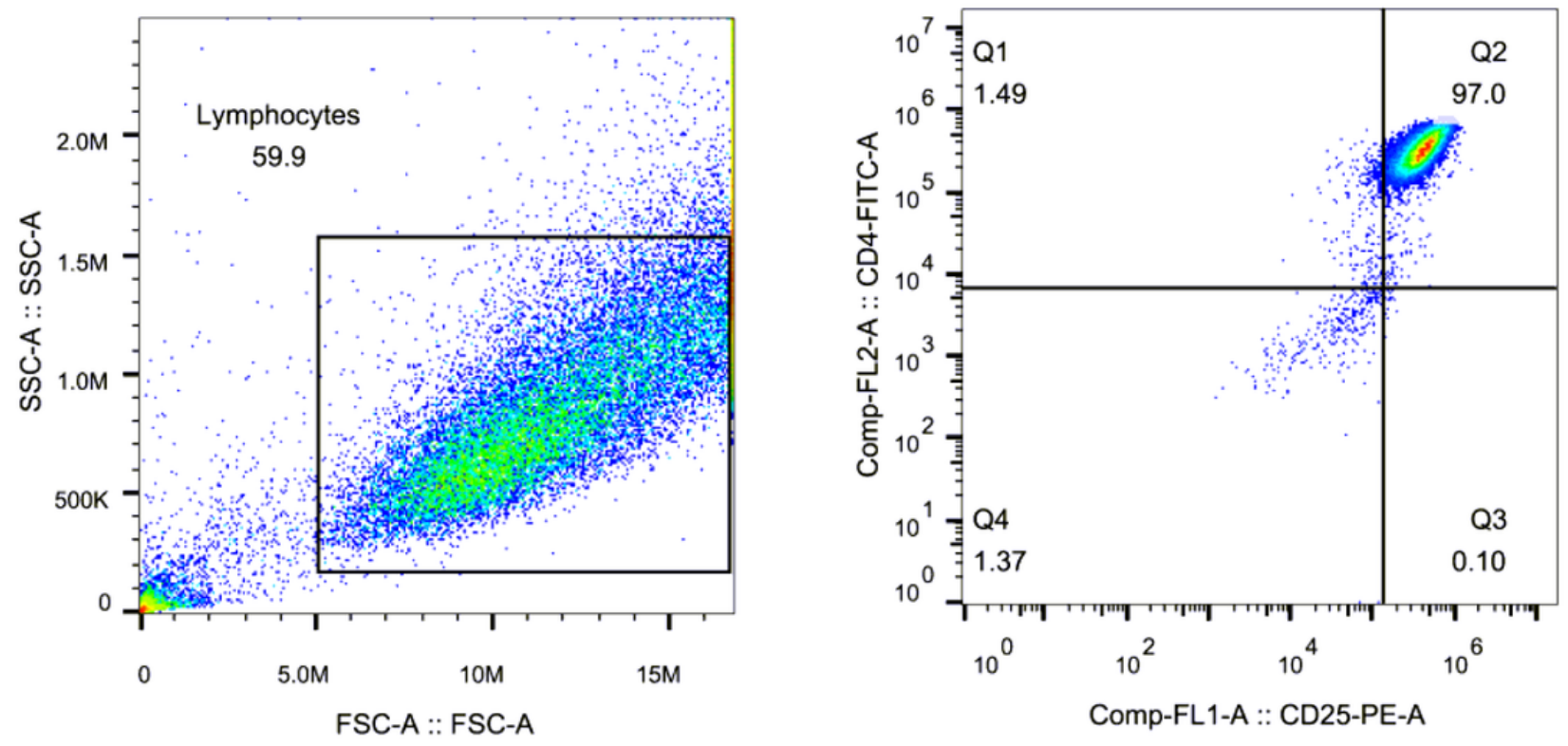

(a)
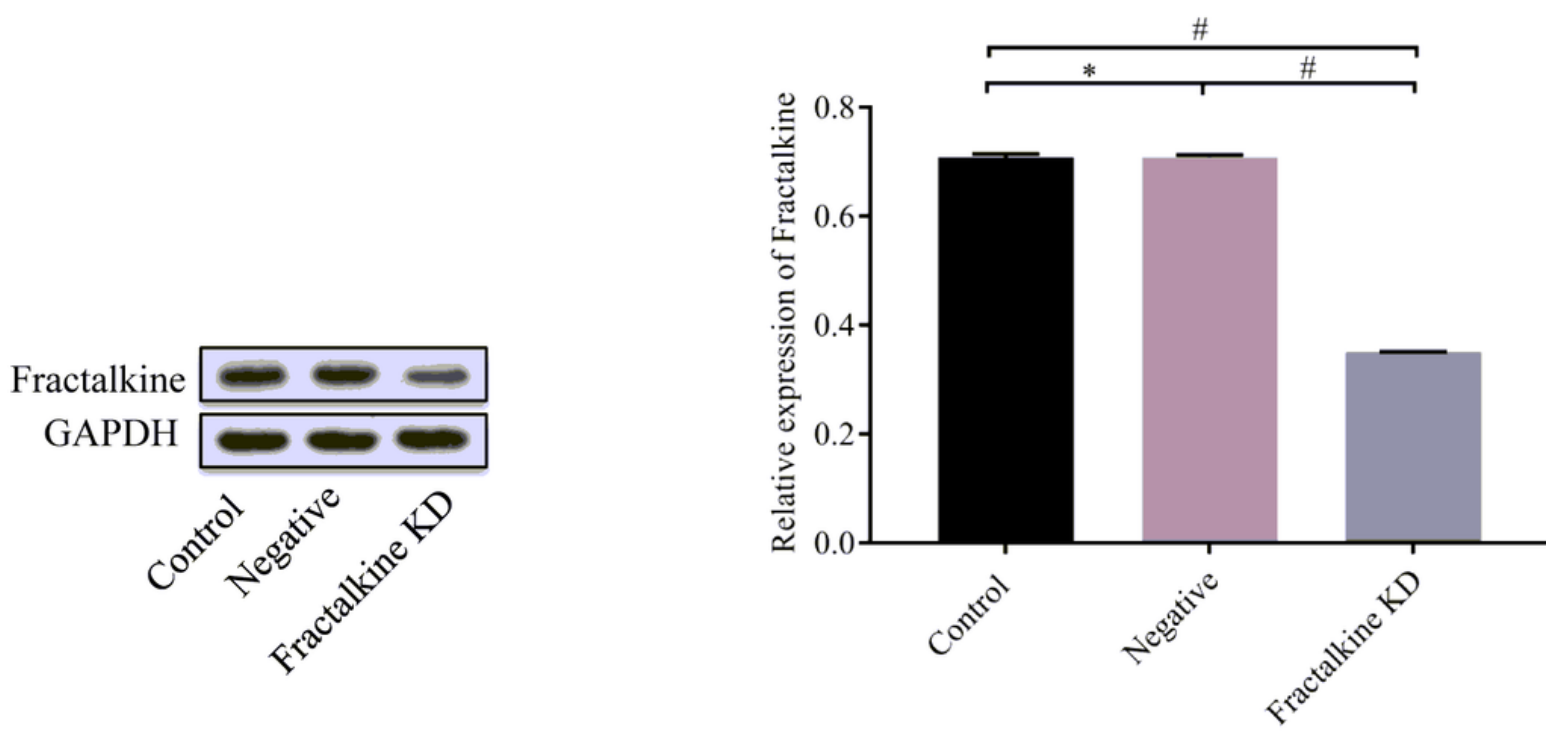

(b)

\section{Figure 5}

Treg cell purity and expression of Fractalkine protein after transfection of Treg cells Purified CD4+ CD25+ T cells from LN mice were stained with FITC-labelled anti-CD4 and PE-conjugated anti-CD25 antibodies. The CD25 expression levels on purified CD4+ CD25+ T cells are shown in the upper right quadrant of these representative FACS plots of all performed purifications. (a). Treg cells from lupus mice were transfected with lentiviral vector-CX3CL1 to induce Fractalkine knockdown (KD), or with hU6-MCS-CMV-RFP negative control. Fractalkine KD was verified by western blot (b). $\# p<0.01$ vs. control group, ${ }^{*} p>0.05$ compared to the negative group. Data are presented as the mean \pm SD of three independent experiments performed in triplicate. 

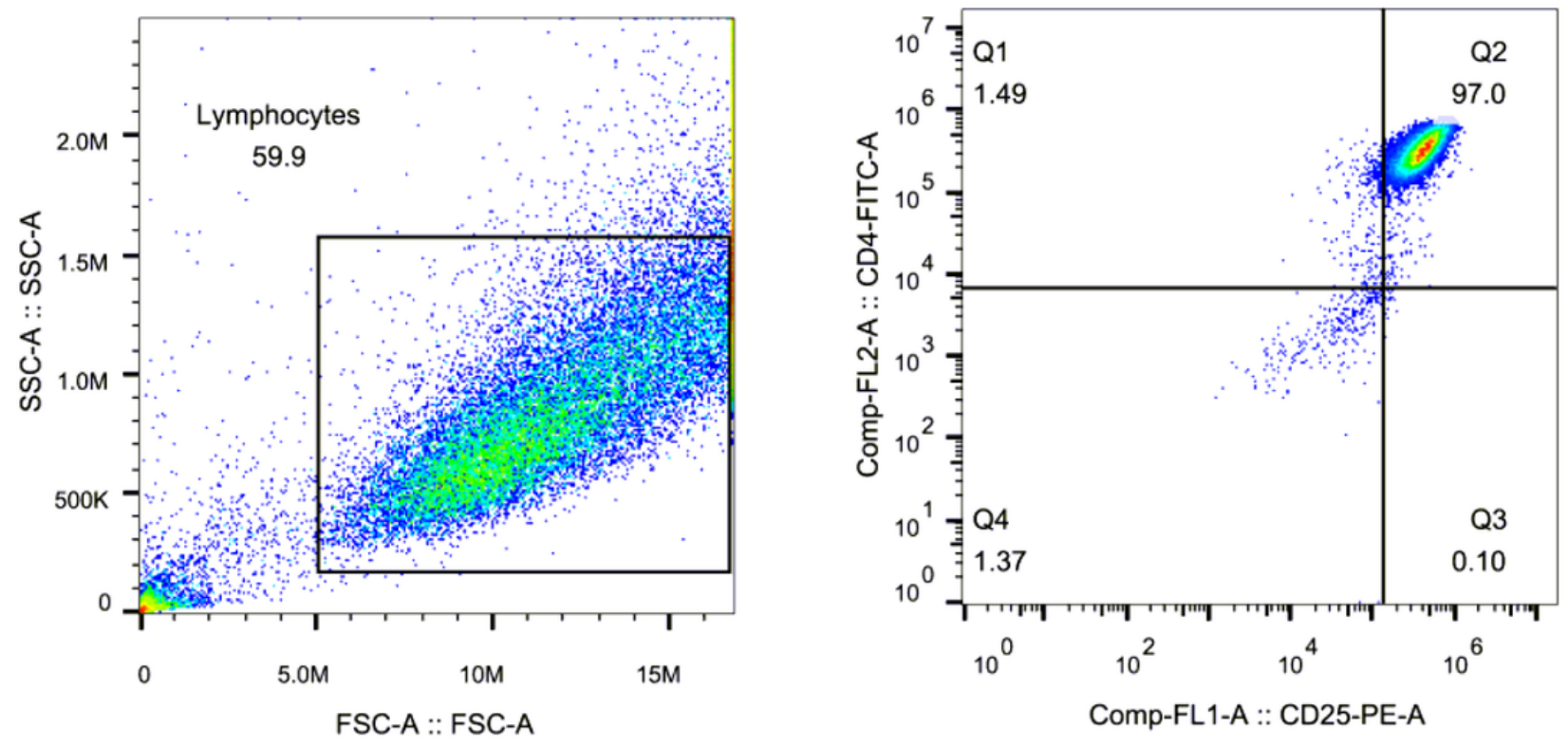

(a)
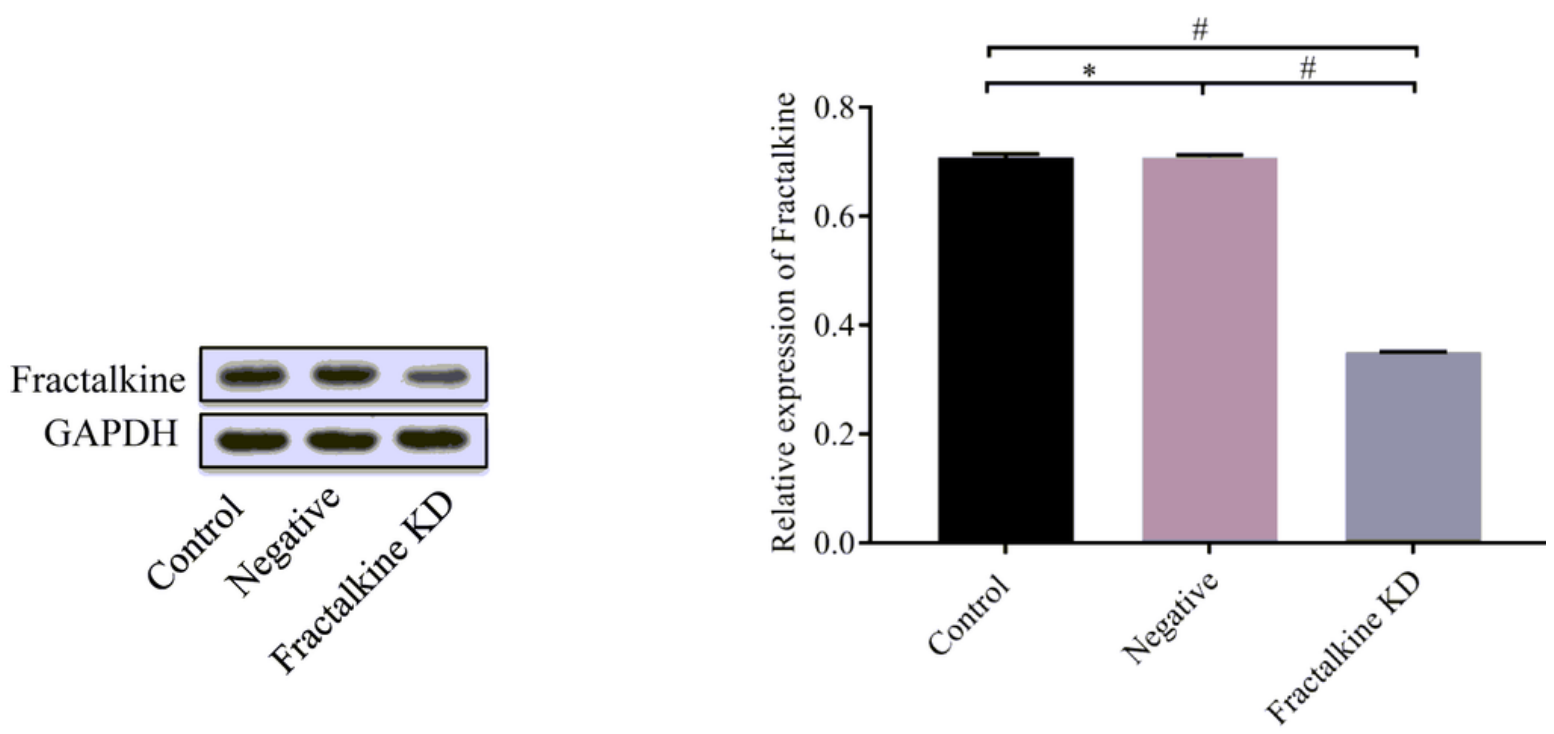

(b)

\section{Figure 5}

Treg cell purity and expression of Fractalkine protein after transfection of Treg cells Purified CD4+ CD25+ T cells from LN mice were stained with FITC-labelled anti-CD4 and PE-conjugated anti-CD25 antibodies. The CD25 expression levels on purified CD4+ CD25+ T cells are shown in the upper right quadrant of these representative FACS plots of all performed purifications. (a). Treg cells from lupus mice were transfected with lentiviral vector-CX3CL1 to induce Fractalkine knockdown (KD), or with hU6-MCS-CMV-RFP negative control. Fractalkine KD was verified by western blot (b). $\# p<0.01$ vs. control group, ${ }^{*} p>0.05$ compared to the negative group. Data are presented as the mean \pm SD of three independent experiments performed in triplicate. 


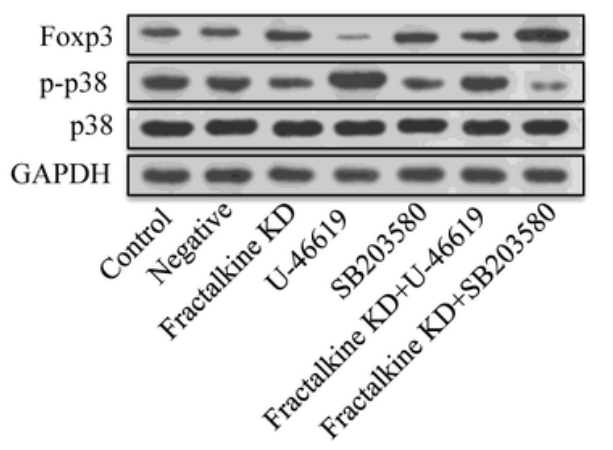

(a)

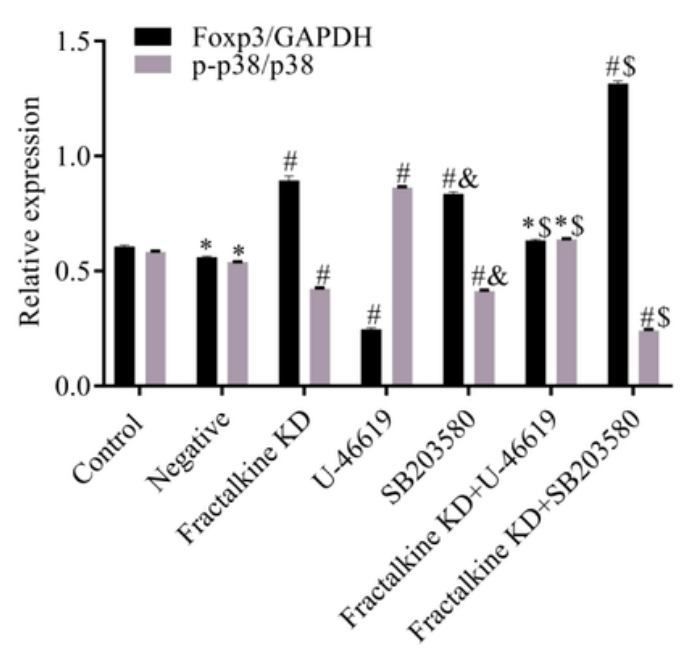

(b)

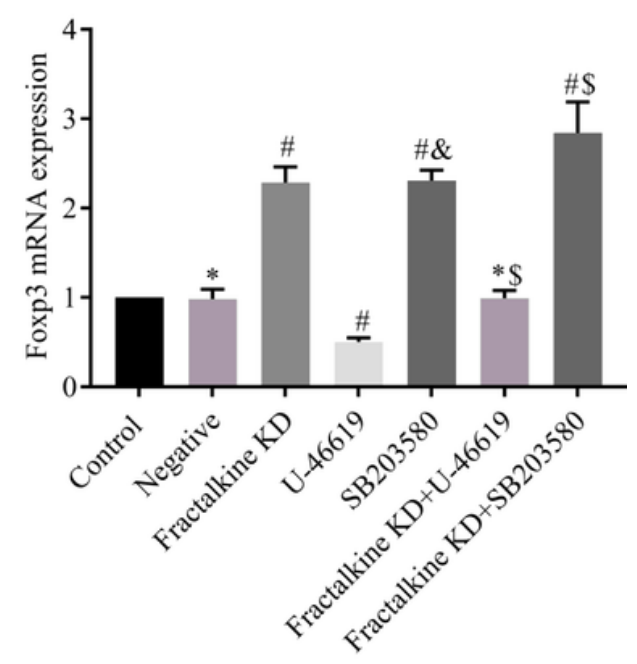

(c)

\section{Figure 6}

Inhibition of Foxp3 expression via Fractalkine by activating p38MAPK in Treg cells from lupus mouse Foxp3 and p38MAPK protein expression according to western blot $(a, b)$. Foxp3 mRNA expression according to quantitative RTPCR (c). \#p < 0.05 vs. control; \#\$p < 0.05 vs. SB203580; \#\&p > 0.05 vs. Fractalkine KD; $* p>0.05$ vs. control; $* \$ P>0.05$ vs. control. Data are presented as the mean \pm SD of three independent experiments performed in triplicate.

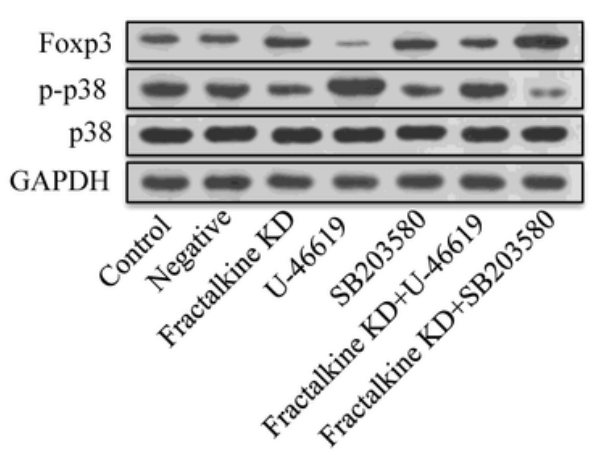

(a)

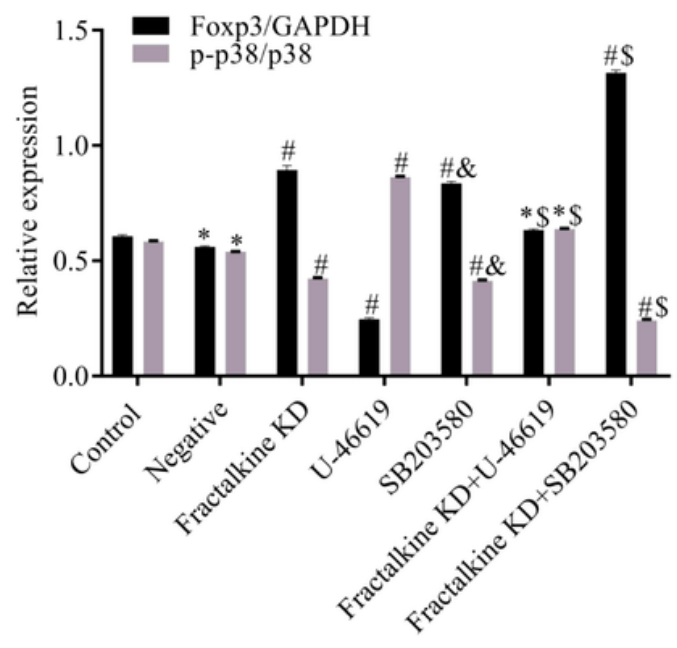

(b)

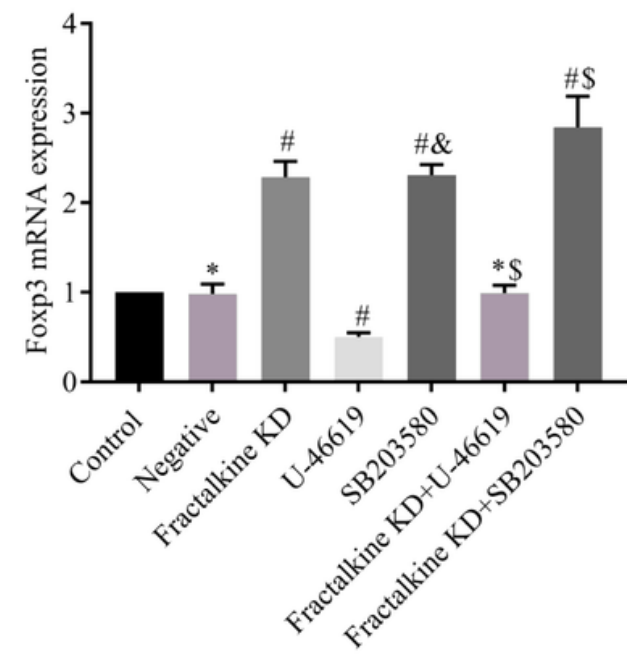

(c)

\section{Figure 6}

Inhibition of Foxp3 expression via Fractalkine by activating p38MAPK in Treg cells from lupus mouse Foxp3 and p38MAPK protein expression according to western blot $(a, b)$. Foxp3 mRNA expression according to quantitative RTPCR (c). \#p < 0.05 vs. control; \#\$p < 0.05 vs. SB203580; \#\&p > 0.05 vs. Fractalkine KD; *p > 0.05 vs. control; *\$P >0.05 vs. control. Data are presented as the mean \pm SD of three independent experiments performed in triplicate. 
(a)
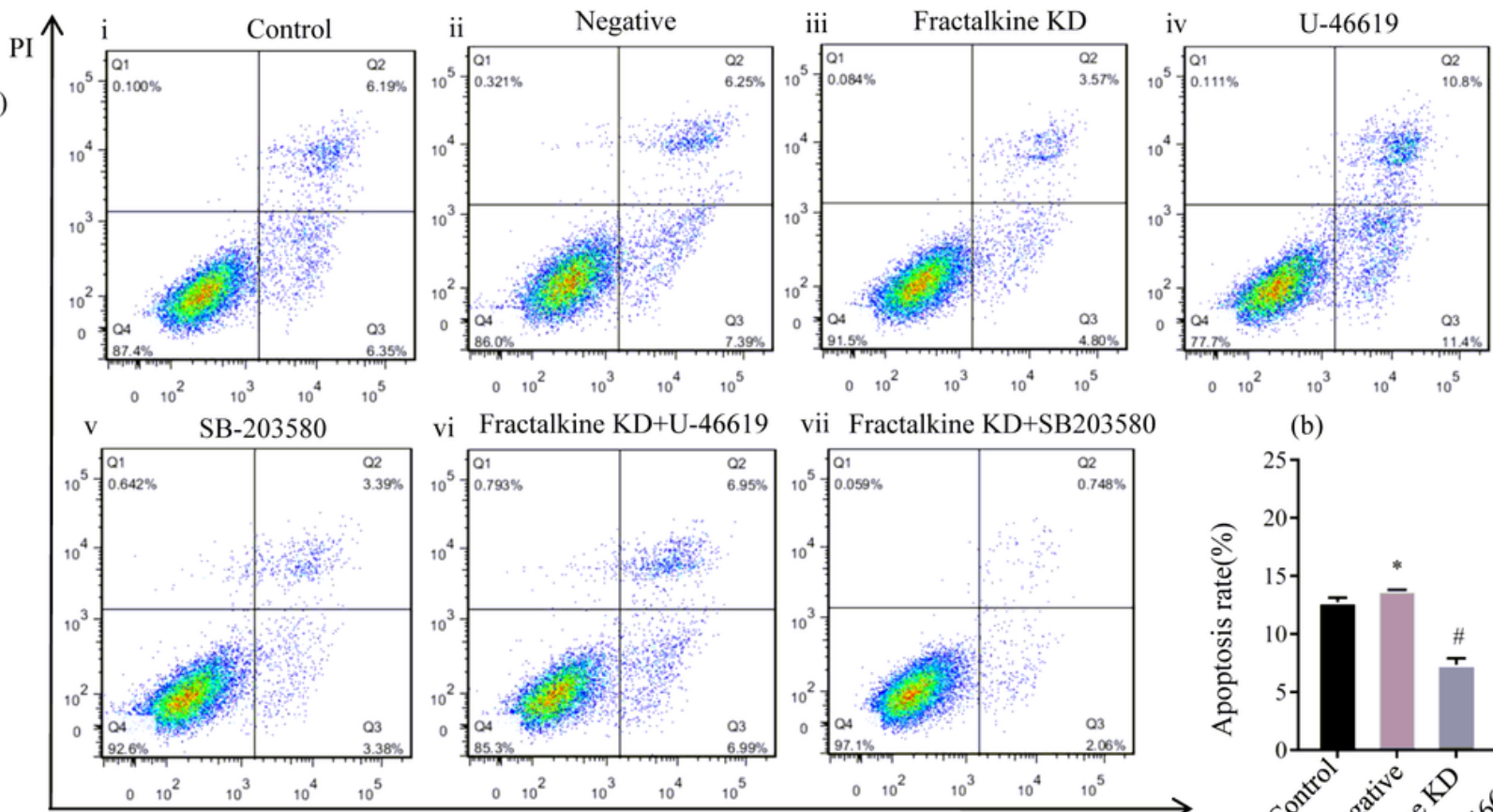

vi Fractalkine KD+U-46619

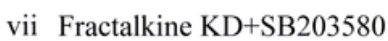

(b)
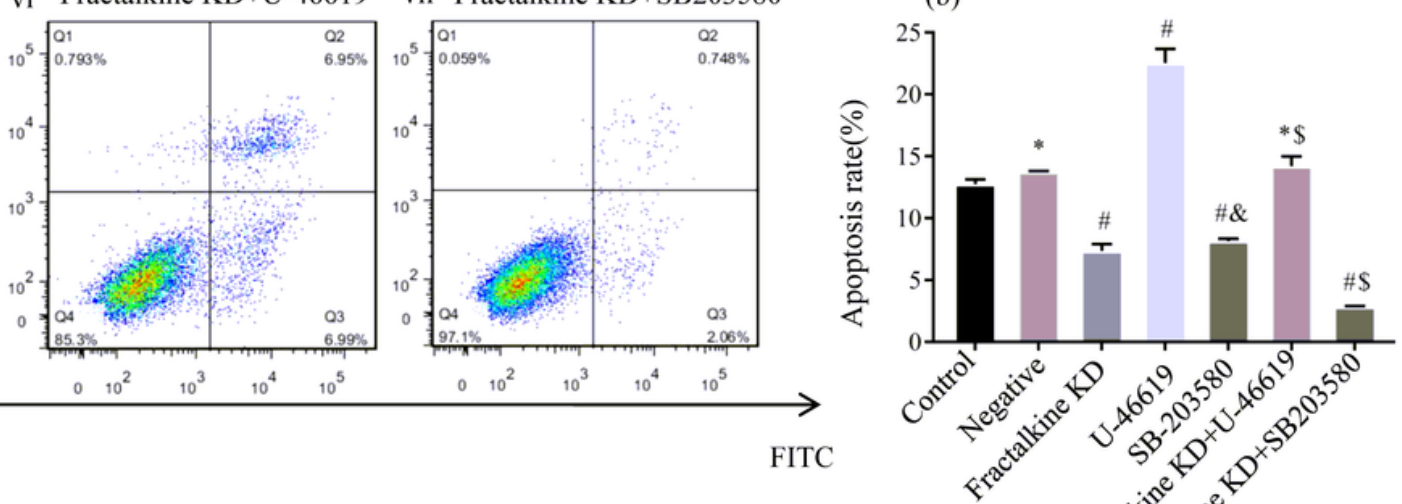

(c)

(d)

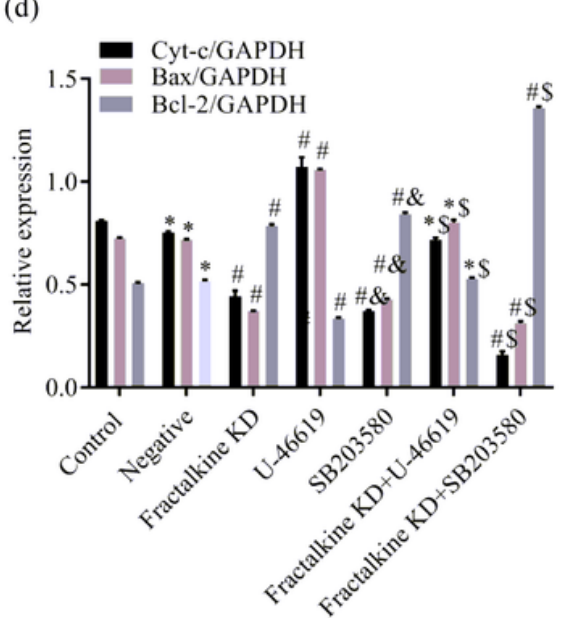

(e)

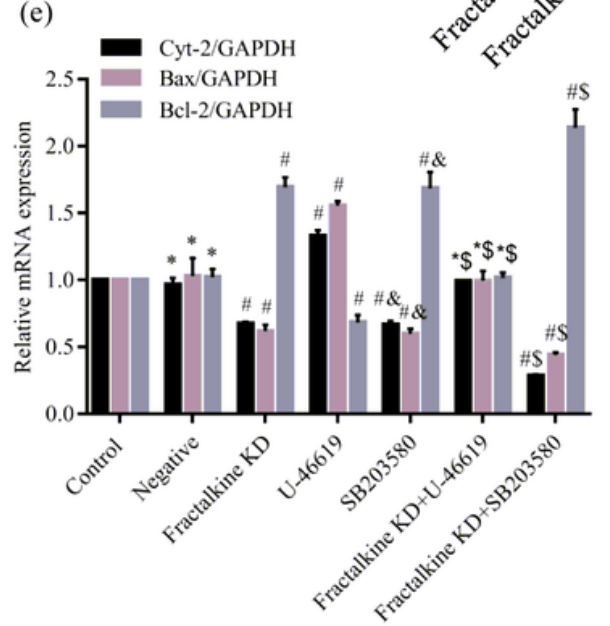

Figure 7

Detection of Treg cell apoptosis after different treatments by Annexin V-FITC and PI staining (a). Incubation of Treg cells from lupus mouse with annexin V-FITC and PI for $48 \mathrm{~h}$ and flow cytometry analysis. The upper right quadrant shows annexin-positive cells (early apoptotic). The upper left quadrant shows only PI-positive cells (necrotic). The lower right quadrant shows annexin- and PI-positive cells (late apoptotic cells). (i) Con; (ii) Negative; (iv) Fractalkine KD; (v) U-46619; (vi) SB203580; (vi) Fractalkine KD + U-46619; (vii) Fractalkine KD + SB203580. (b) Apoptotic to total cells ratio. Histogram indicating the ratio of early apoptotic cells (Q3). Western blot (c, d) and quantitative RT-PCR (e) Detection of Bax, Bcl-2, and Cyt-c protein and mRNA levels. \#p < 0.05 vs. control; \#\$p< 0.05 vs. SB203580; \#\&p > 0.05 vs. Fractalkine KD; $* p>0.05$ vs. control; $* \$ P>0.05$ vs. control. Data are presented as the mean $\pm S D$ of three independent experiments performed in triplicate. 
(a)
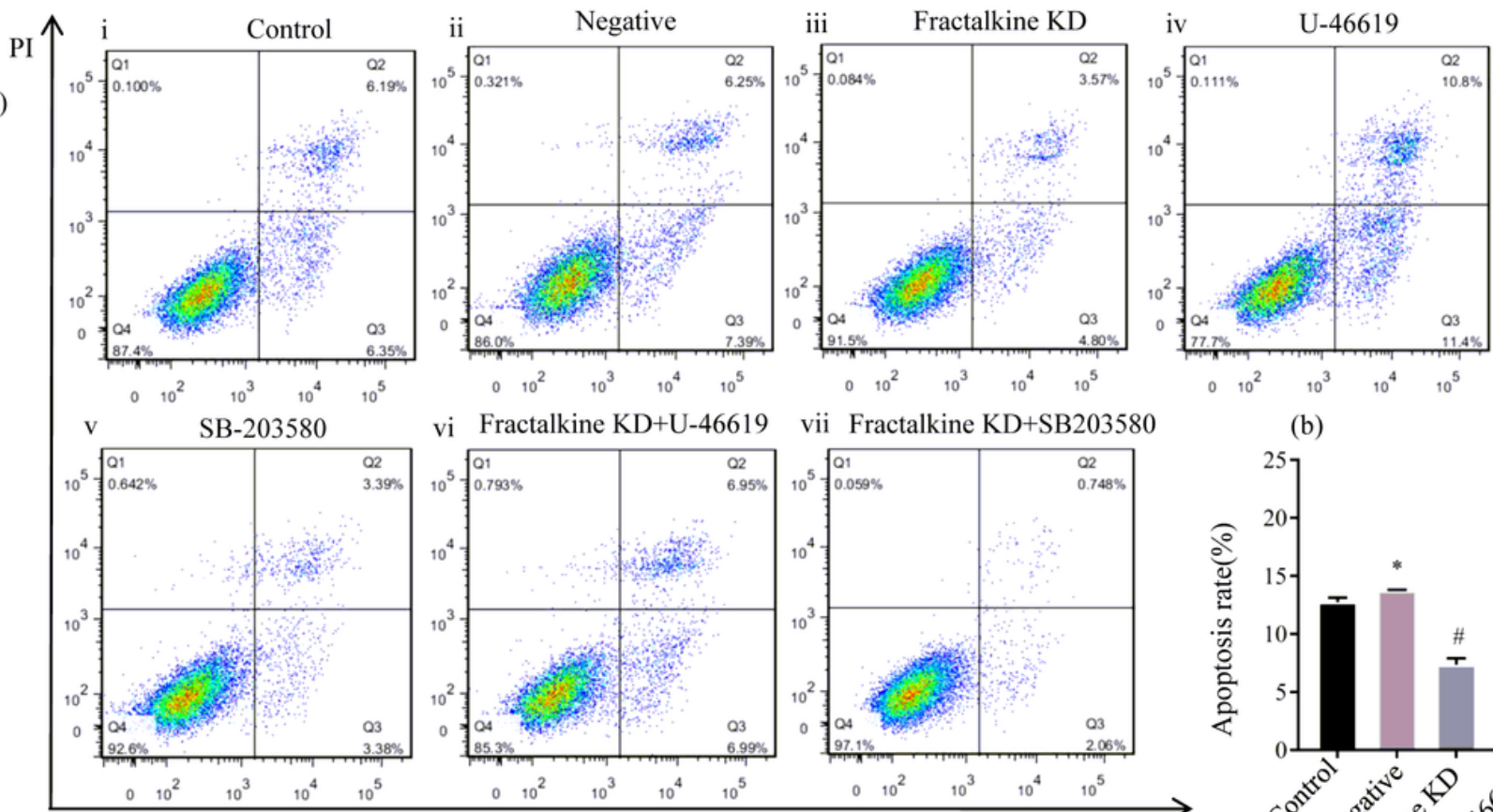

vi Fractalkine KD+U-46619

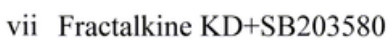

(b)
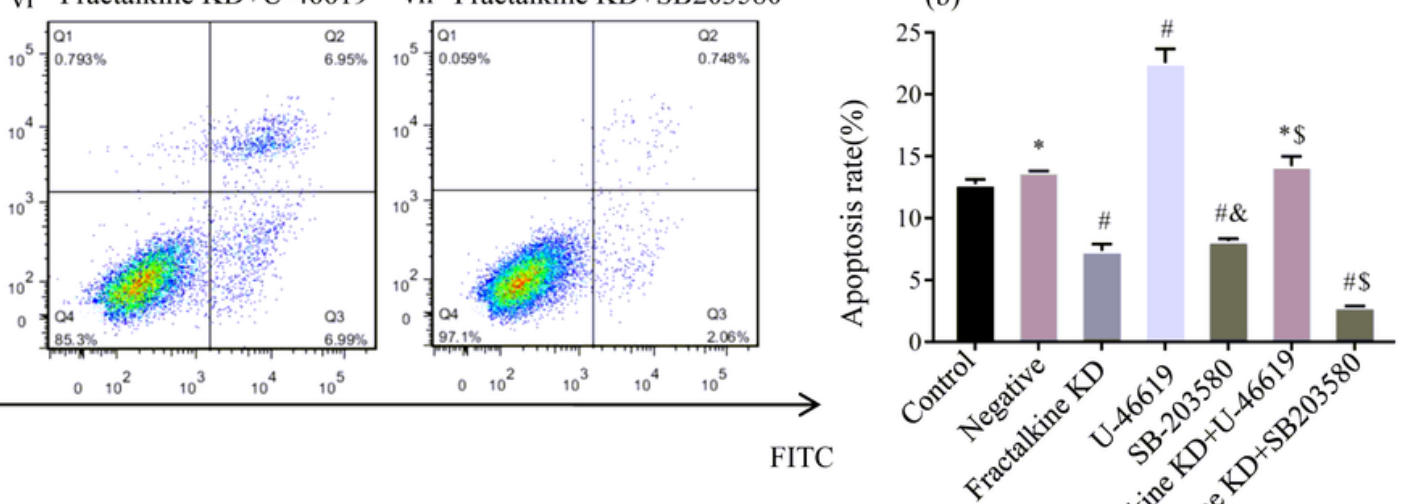

(c)

(d)

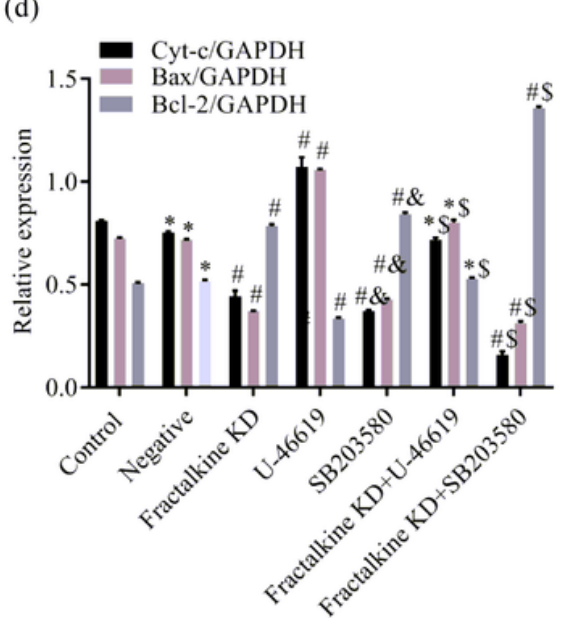

(e)

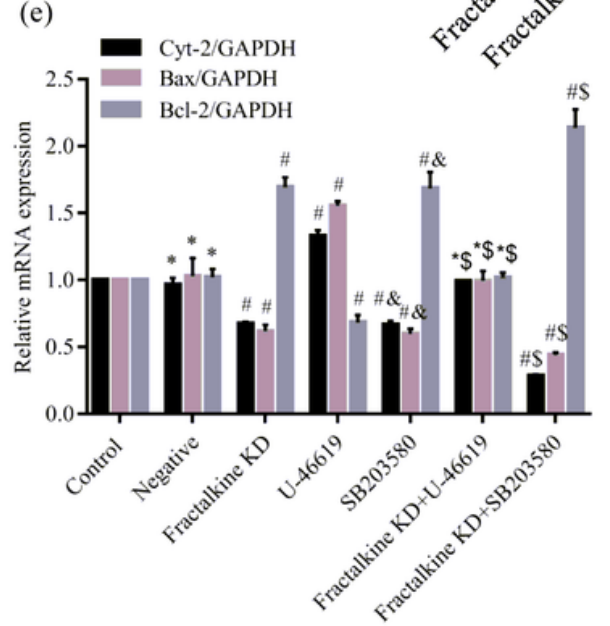

Figure 7

Detection of Treg cell apoptosis after different treatments by Annexin V-FITC and PI staining (a). Incubation of Treg cells from lupus mouse with annexin V-FITC and PI for $48 \mathrm{~h}$ and flow cytometry analysis. The upper right quadrant shows annexin-positive cells (early apoptotic). The upper left quadrant shows only PI-positive cells (necrotic). The lower right quadrant shows annexin- and PI-positive cells (late apoptotic cells). (i) Con; (ii) Negative; (iv) Fractalkine KD; (v) U-46619; (vi) SB203580; (vi) Fractalkine KD + U-46619; (vii) Fractalkine KD + SB203580. (b) Apoptotic to total cells ratio. Histogram indicating the ratio of early apoptotic cells (Q3). Western blot (c, d) and quantitative RT-PCR (e) Detection of Bax, Bcl-2, and Cyt-c protein and mRNA levels. \#p < 0.05 vs. control; \#\$p< 0.05 vs. SB203580; \#\&p > 0.05 vs. Fractalkine KD; $* p>0.05$ vs. control; $* \$ P>0.05$ vs. control. Data are presented as the mean $\pm S D$ of three independent experiments performed in triplicate. 